DIW BERLIN

Discussion

Papers
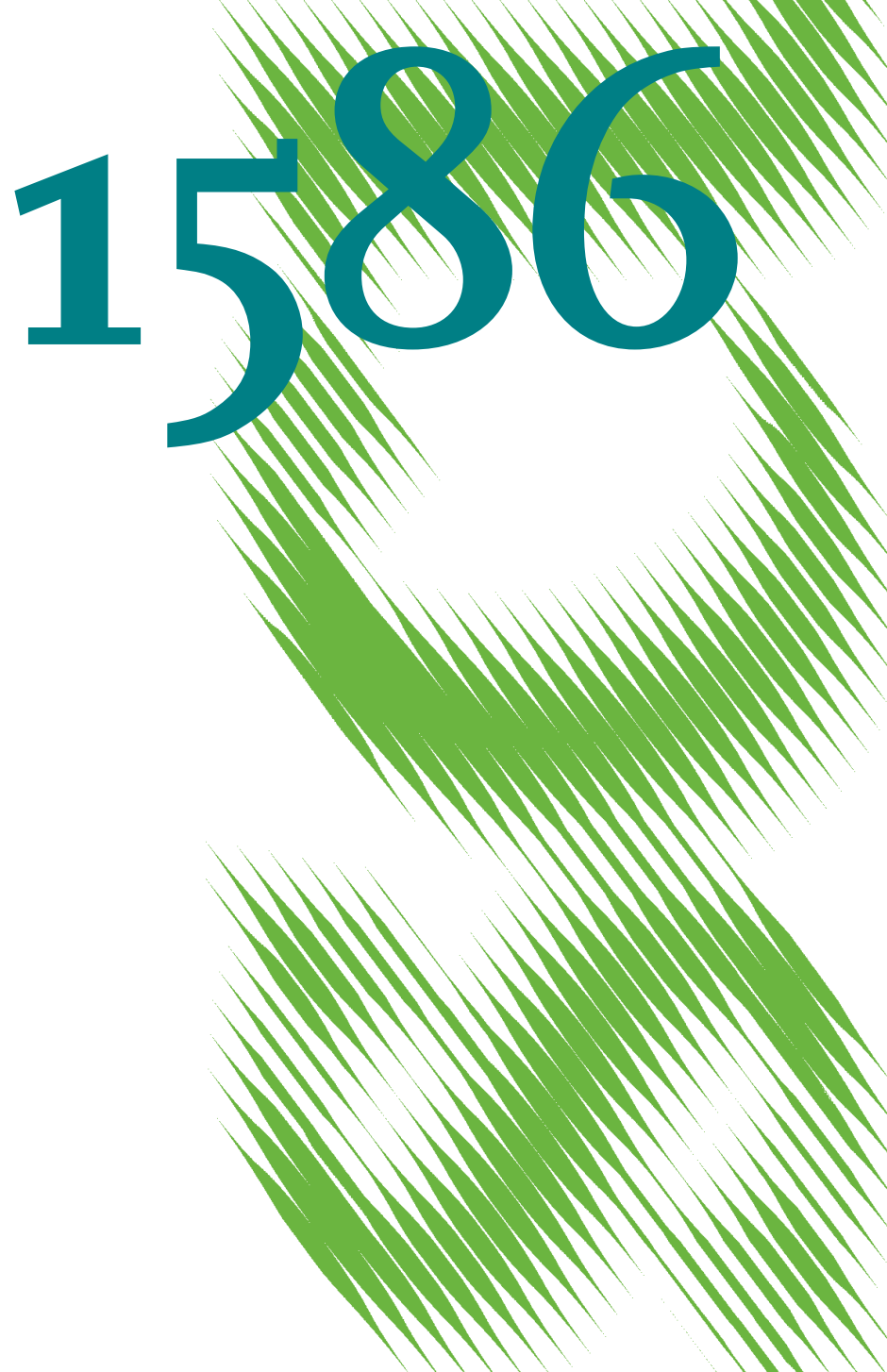

Locus of Control and Mothers' Return to Employment 
Opinions expressed in this paper are those of the author(s) and do not necessarily reflect views of the institute.

IMPRESSUM

(C) DIW Berlin, 2016

DIW Berlin

German Institute for Economic Research

Mohrenstr. 58

10117 Berlin

Tel. +49 (30) $89789-0$

Fax +49 (30) $89789-200$

http://www.diw.de

ISSN electronic edition 1619-4535

Papers can be downloaded free of charge from the DIW Berlin website:

http://www.diw.de/discussionpapers

Discussion Papers of DIW Berlin are indexed in RePEc and SSRN:

http://ideas.repec.org/s/diw/diwwpp.html

http://www.ssrn.com/link/DIW-Berlin-German-Inst-Econ-Res.html 


\title{
Locus of Control and Mothers' Return to Employment
}

\author{
Eva M. Berger* \\ Johannes Gutenberg University Mainz
}

Luke Haywood

DIW Berlin

\begin{abstract}
This paper investigates the effect of locus of control (LOC) on the length of mothers' employment break after childbirth. Using data from the German Socio-Economic Panel Study (SOEP), duration data reveals that women with an internal LOC return to employment more quickly than women with an external LOC. We find evidence that this effect is mainly related to differential appreciation of the career costs of longer maternity leave. Given the high level of job protection enjoyed by mothers in Germany, economic consequences of differences in this noncognitive skill can be expected to be larger in other settings.
\end{abstract}

Keywords: Locus of Control, Noncognitive Skills, Personality, Maternal Employment, Female Labor Supply, Survival Analysis

JEL-codes: J22, J24

${ }^{*}$ Corresponding author: Johannes Gutenberg University Mainz, Jakob-Welder-Weg 4, 55128 Mainz, Germany. Phone: +49(0)6131-39-27295. Fax.: +49(0)6131-39-27695. E-mail: eva.berger@uni-mainz.de. 


\section{Introduction}

Recent research on so-called noncognitive skills ${ }^{1}$ demonstrates their crucial role for educational attainment, employment outcomes, and a variety of risky behaviors (Blomeyer et al. 2009, Coleman and DeLeire 2003, Heckman et al. 2006, Piatek and Pinger 2015). In the labor market, a number of studies find that noncognitive skills affect earnings (Andrisani 1977, 1981, Cebi 2007, Flossmann et al. 2007, Heckman and Rubinstein 2001, Heckman et al. 2006, Heineck and Anger 2010, Mueller and Plug 2006, Nyhus and Pons 2005, Osborne Groves 2005) and unemployment duration (Uhlendorff 2004, Uysal and Pohlmeier 2009). ${ }^{2}$ In the present study, we test whether and how locus of control (LOC) affects women's decision how long to stay out of employment after childbirth, a crucial determinant of female labor supply and related to the female wage gap (Blundell et al. 2013, Adda et al. 2016).

While the effect of various noncognitive skills on employment outcomes has been studied, little is known about its association with labor supply decisions. ${ }^{3}$ We focus on one such noncognitive skill, LOC. It describes "individual differences in a generalized belief for internal versus external control of reinforcement" (Rotter 1966, p. 1). LOC is then a measure of the degree to which an individual perceives that success or failure in life follows from her own behavior rather than being controlled by outside forces. If life events are perceived by a person as being contingent upon her own behavior or her own characteristics, this characterizes an internal LOC. If, on the other hand, life events are perceived by a person as the result of luck, chance, fate, or under the control of powerful others, this is labeled an external LOC. ${ }^{4}$ Using a common factor of the Rotter LOC scale and the Rosenberg self-esteem scale, Heckman et al. (2006) find that the impact of noncognitive skills on the employment probability is greater

\footnotetext{
${ }^{1}$ We use the term non-cognitive skills as it is used in a large part of the related literature (see, e.g., Cunha and Heckman 2007, 2008). These skills refer to abilities and personality traits other than pure cognitive ability. Nevertheless, we are aware that most of these skills or traits do have a cognitive component.

${ }^{2}$ Furthermore, a number of studies in psychology investigate the relationship between personality traits and occupational attainment (see (Roberts et al. 2007)).

${ }^{3}$ Wichert and Pohlmeier (2010) find a relationship between women's big five personality traits and their labor force participation. For a detailed discussion of the research on noncognitive skills in economics and psychology, see Borghans et al. (2008).

${ }^{4}$ Following the original concept of LOC by Rotter (1966), we use a single index of LOC where internal and external are the opposite poles of a single dimension. This aspect is discussed in detail in appendix A.
} 
than the effect of cognitive skills. Moreover, they find that this pattern is more pronounced for women than for men, suggesting that noncognitive skills matter particularly for women's labor supply. Departing from this observation, the present paper focuses on a particularly important labor supply decision for women-when to re-enter the labor market after childbirth. Since noncognitive skills—-though largely stable throughout adulthood-are malleable during childhood (Cunha and Heckman 2007, 2008), the current study adds to the evidence suggesting that early childhood investments may have long-lasting effects (Carneiro et al. 2011, Cunha and Heckman 2009).

Post-birth employment behavior matters because it affects human capital accumulation, future employment chances and wages (Davies and Pierre 2005, Gutierrez-Domenech 2005, Lefebvre et al. 2009). Furthermore, maternal employment plays a large role in counteracting the risk of child poverty, an important policy issue. Most studies on mothers' return to employment focus on institutional factors such as parental leave schemes or tax rules (e.g., Bergemann and Riphahn 2009, 2010, Burgess et al. 2008, Gutierrez-Domenech 2005), or on individual and family-related factors such as income, educational attainment, and labor market experience (Kuhlenkasper and Kauermann 2010).

The present paper thus contributes to two strands of the literature: First, the economic consequences of noncognitive skills; second, the determinants of mothers' return to employment after childbearing. We focus on LOC and test several channels through which LOC could influence the length of employment breaks women take after a childbirth. First, LOC might affect women's labor market attachment, viz. their willingness to be available all day for their children. Second, LOC may affect the relative importance given to uncertain material gains associated with earlier return to the labor market.

The paper is organized as follows: Section 2 presents a simple model which provides us with a framework to test various channels by which LOC may influence maternal return to employ- 
ment. Section 3 gives details on the data from the German Socio-Economic Panel (SOEP) that we use. Section 4 describes our reduced-form estimation strategy based on a semi-parametric survival model. Section 5 presents and discusses our main results: women with more internal LOC return to the labor market quicker because they are more sensitive to the career costs associated with long leave durations. Section 6 concludes.

\section{A Model of Return to Employment After Childbirth}

The economic consequences of mothers' decision when to return to the labor market after giving birth are very large (Adda et al. 2016) since human capital accumulates in employment. Work experience can then be seen as a form of investment in human capital (Blundell et al. 2013). Coleman and DeLeire (2003) find that persons with an internal LOC make higher investments in human capital than persons with an external LOC. They argue that the benefits of human capital investment are appreciated more strongly by individuals with an internal LOC compared to individuals with an external LOC since the latter believe that future earnings depend more strongly on factors over which they have no influence. The same argument applies to an earlier return to work since this also leads to more work experience and can thus be seen as an investment in human capital.

Importantly, while a more internal LOC is associated with a higher job search intensity by unemployed persons (Caliendo et al. 2015, Spinnewijn 2015), our setting allows us to highlight other aspects. Mothers in Germany benefit from a legal right to return to their previous position (at the same wage) within three years after childbirth. Hence, mothers can freely decide about the length of their leave without fearing to lose their job position or have their wage level cut on returning - they do not need to search for a new job. ${ }^{5}$ In practice very few mothers are observed to enter new jobs after maternity leave, so that career costs do not arise as a result of differences in job search during maternity leave. In particular, mothers on leave report extremely low

\footnotetext{
${ }^{5}$ Obviously, job protection is only helpful for mothers who have a permanent contract or whose temporary job does not expire during maternity leave. We do a robustness test of our main estimations below including only those women in the sample who have a permanent job prior to first childbirth. Our results are robust.
} 
search intensity, significantly less than unemployed and even employed individuals: Only 4\% of women on leave in the first year after birth report active job search activities in the previous month, rising to only $9 \%$ and $12 \%$ in the second and third year after birth. This is significantly less than a comparable sample of unemployed individuals of whom $66 \%$ report to have been actively searching for work in the last month. We believe our evidence about the effect of LOC on return to work thus highlights a different channel: differential appreciation of future wage growth.

Even though mothers have the legal right to return to their previous position at the same wage, the duration of leave might have consequences for their future career prospects. For example, the probability of future promotions might be reduced for mothers taking long leaves. Expectations about these consequences might vary across individuals: Women with a more internal LOC might fear stronger negative consequences than women with a more external LOC.

In the following section we formalize this intuition, allowing mothers to determine the duration of leave to maximize their expected net present value of lifetime utility, comparing the value of leave to that of work. We use this model to determine the factors we investigate in a framework of duration models.

\subsection{The Model}

To inform our empirical results, we now present a simple model of return to the labor market based on the German institutions of job protection. Mothers' instantaneous utility $u($.$) depends$ on the material and non-material benefits of staying at home with the child $b(d)$, a function of leave duration $d$. Utility also depends on other household income $m$, which can strongly influence mothers' net income given joint household taxation in Germany. On returning to the labor market, mothers receive their pre-childbirth wage level $w_{0}$, in line with German job protection, 
which extends until 36 months of maternity leave.

We believe that future wage growth prospects vary significantly as a function of maternity leave duration. We do not discuss what causes these differences. A possible mechanism is that wage offers reflect the latent productivity of returning mothers. The reduction in wage offers would thus reflect the depreciation of human capital during maternity leave. Another reason may be discrimination by employers.

In line with the literature on job search, we model wage growth as workers receiving job offers from a wage distribution $F($.$) at Poisson rate \lambda$. Dechter (2014) and Schmieder et al. (2015) find that periods out of the labor market are followed by a reduction in job offers. We thus allow for mothers to receive fewer offers when returning later to the labor market. Assuming mothers accept offers with a higher wage than in their current job, this then translates to a lower wage growth rate for mothers with longer maternity leave spells. We also allow the job arrival rate $\lambda$ to be a function of individual unobserved characteristics $X$ (including LOC-as previous evidence suggests that LOC influences job search intensity and this may likewise be the case for job search intensity on-the-job ${ }^{6}$ ).

Since benefits of earlier return to the labor market are in the future and thus uncertain, these might be appreciated differentially by individuals depending on their LOC. LOC is a noncognitive skill related to beliefs, it plays a role in situations of uncertainty; i.e., individuals form expectations about the net present value of labor market re-entry according to their LOC. We operationalize this using an expectations operator $\tilde{E}_{\lambda}^{L O C}$, indicating that differences in $L O C$ translate to differences in beliefs about $\lambda$. We can then give the net present value of being in

\footnotetext{
${ }^{6}$ Though we assume that mothers do not search during leave, we do allow for job search on-the-job, both prior to childbirth as well as after re-entry. This is how we model wage growth.
} 
maternity leave, $V($.$) , and that of being employed, W($.$) , discounted by the interest rate r$ as

$$
\begin{aligned}
V\left(b, m, d, w_{0}\right) & =\frac{u(b(d), m)}{r}+\frac{1}{r}\left[\max \left[V(b, m, d), W\left(w_{0}, m, d\right)\right]-V(b, m, d)\right] \\
W(w, m, d) & =\frac{u(w, m)}{r}+\frac{1}{r} \tilde{E}_{\lambda}^{L O C}\left[\lambda(X, d) \int \max \left[W\left(w^{\prime}, m, d\right), W(w, m, d)\right]-W(w, m, d) d F\left(w^{\prime}\right)\right]
\end{aligned}
$$

These continuous-time Bellman equations are often presented in terms of asset value formulations

$$
\begin{aligned}
r V(b, m, d) & =u(b(d), m)+\max \left[W\left(w_{0}, m, d\right), V(b, m, d)\right]-V(b, m, d) \\
r W(w, m, d) & =u(w, m)+\tilde{E}_{\lambda}^{L O C}\left[\lambda(X, d) \int \max \left[W\left(w^{\prime}, m, d\right), W(w, m, d)\right]-W(w, m, d) d F\left(w^{\prime}\right)\right] .
\end{aligned}
$$

The structure of these expressions closely follows the "fundamental equation of search" for the unemployed (Pissarides 2001). First, the flow utility $u(b(d), m)$ depends on other household income $m$ and enjoyment of staying at home during maternity leave, $b(d)$. We expect both the material and non-material components of $b(d)$ to be decreasing with the duration of maternity leave $d$. Second, at any point in time during the first 36 months of maternity leave, mothers may decide to move back into employment. We expect this to occur when $W($.$) exceeds V($.$) ,$ explaining the maximum operator in equation (1).

Equation (2) gives the value of being employed. This has a similar structure to that of being in maternity leave: First, flow utility is given by the instantaneous utility of work depending on wage $w$ and other household income. Second, with some probability $\lambda($.$) , individuals receive$ job offers from a wage distribution with the cumulative distribution function $F($.). When an offer $w^{\prime}$ is accepted, the employment value increases to $W\left(w^{\prime}, m, d\right)$ - the maximum operator indicates that only offers are accepted which increase the employment value. This is the case for any offer that pays higher wages - and this is the way we model wage growth. Note that we allow the rate of new job offers after return to the labor market to depend on LOC (as part of $X$ ) and maternity duration $d$. Additionally, we allow individuals with different LOC to have different beliefs about the probability of job offers arising. In particular, the literature reviewed 
above suggests that individuals with internal LOC may expect stronger consequences of own behavior on wage growth than individuals with external LOC. Thus, individuals with an internal LOC may expect stronger consequences of maternity leave duration on wage growth (beliefs about $\partial \lambda / \partial d)$.

A young mother then chooses her optimal duration of maternity leave, $d^{*}$, such that $V\left(b, m, d^{*}\right)=$ $W\left(w_{0}, m, d^{*}\right)$, which implies

$u\left(b\left(d^{*}\right), m\right)=u\left(w_{0}, m\right)+\tilde{E}_{\lambda}^{L O C}\left[\lambda\left(d^{*}, L O C\right)\left[\int \max \left[W\left(w^{\prime}, m, d^{*}\right), W\left(w_{0}, m, d^{*}\right)\right]-W\left(w_{0}, m, d^{*}\right) d F\left(w^{\prime}\right)\right]\right]$.

Expression (3) implicitly defines the optimal time of return to the labor market $\left(d^{*}\right)$ as a function of the level of pre-birth earnings $w_{0}$ (as this is equal to wage at re-entry), other household earnings $m$, and the option value related to future wage growth—beliefs about which may be moderated by LOC. In order to gain an estimable expression, we note that the expression in the expectations-term is related only to wage gains in the future, thus is a function of wage growth. Therefore we can write

$$
u\left(b\left(d^{*}\right), m\right)=u\left(w_{0}, m\right)+\tilde{E}_{\Delta w}^{L O C}\left[T\left(\Delta w\left(d^{*}, w_{0}, m, X\right)\right)\right]
$$

where $T($.$) is a function ensuring that (3) is satisfied. The above formulation implies the$ following paths by which LOC may determine return to the labor market:

1. Pre-birth wage rate $w_{0}$-moderated by other household income $m$. The pre-birth wage rate may also be a function of characteristics $X$ and thus of LOC, e.g., as a result of differences in eliciting outside offers due to differences in job search intensity on-the-job before childbirth (Spinnewijn 2015). ${ }^{7}$

\footnotetext{
${ }^{7}$ We do not explicitly write $w_{0}(X)$ in order to keep the notation short.
} 
2. Wage growth $\Delta w($.$) . This may be a function of LOC (independently of leave duration),$ again as a result of differences in job search intensity on-the-job.

3. Expectations about the monetary benefits of returning earlier (conditional on all other effects, via $\tilde{E}_{\lambda}^{L O C}$ ). As noted above, by changing perceived control, LOC may influence the relevant expectations (especially for risk-averse individuals). We test two channels for this: (i) wage growth might be appreciated differentially by people according to their LOC; (ii) the effect of $d$ on wage growth post-return (i.e., the wage growth penalty) might be appreciated differentially by people according to their LOC.

4. Utility of staying at home vis-a-vis working. Individuals with different LOC may have related (unobserved) preferences related to staying at home with their child (cf., e.g., Noor 2002).

Section 4 presents our empirical framework to test these channels, especially the channels (3.i) and (3.ii). Channel (4) constitutes a residual explanation in case none of the previous channels (fully) explain the effect of LOC on $d$. However, based on our empirical results below (presented in section 5) we conclude that the residual channel can be neglected as we find channels (1) and (3ii) fully explain the effect of LOC on leave duration.

\section{Data}

The empirical analysis in this paper is based on data from the German Socio-Economic Panel Study (SOEP) 1984-2013, an annual household panel study that is representative of the population in Germany (Wagner et al. 2007). We use data from women who have their first child between 1992 and 2012.

We focus on the return decision of mothers, i.e., the decision to re-enter employment after childbirth and therefore sample women who were employed prior to first childbirth. This allows us to take into account employment characteristics prior to first childbirth and thus to analyze the channels of pre-birth wage level and wage growth. Certainly, the population of employed 
women prior to childbirth is selective. Women who are not employed prior to first childbirth are partly still in education or have some other reason (e.g., health problems) not to participate in the labor force. For this group the decision to enter employment after childbirth is presumably different and our determinants may not be as relevant.

Further, we concentrate on first births because transitions into employment after higher order births are more complex to model. For example, later transitions into employment are related to the space between births and to previous career interruptions due to previous births. Focusing on first birth allows us to control for employment characteristics of the job prior to first birth. We later show that our association of LOC and labor market return is not related to timing of second childbirth.

Women's employment status is observed in the data on a monthly basis from the fourth month after childbirth until they return to employment or until they are censored. ${ }^{8}$. The first three months after childbirth are ignored because new mothers in Germany are not allowed to be employed during the first eight weeks after childbirth; this period extents to twelve weeks for mothers of multiple births or preterm births. Censoring occurs when an individual exits the survey or when the most recent month observed (December 2012) is reached and no transition into employment is observed until this point. Individuals for whom we observe a transition into unemployment ${ }^{9}$ or education are discarded from the sample. In total, the sample contains 18,967 person-month observations from 966 individuals observed between a minimum of one and a maximum of 215 monthly spells (corresponding to 18 years). Average maternity leave duration is 19.6 months (std. dev. 27.3). For $78.8 \%$ of individuals a transition into employment is observed with a mean number of spells of 18.2 (std. dev. 21.9). The remaining $21.2 \%$ are censored and have a mean spell duration of 25.1 (std. dev. 41.3). Figure (1) illustrates the density of spells.

\footnotetext{
${ }^{8}$ The monthly employment status is surveyed retrospectively in each wave; therefore, the latest SOEP wave of 2013 contains information on the monthly employment status until December 2012.

${ }^{9} \mathrm{~A}$ person is defined as unemployed if she is registered as unemployed with the Employment Office.
} 


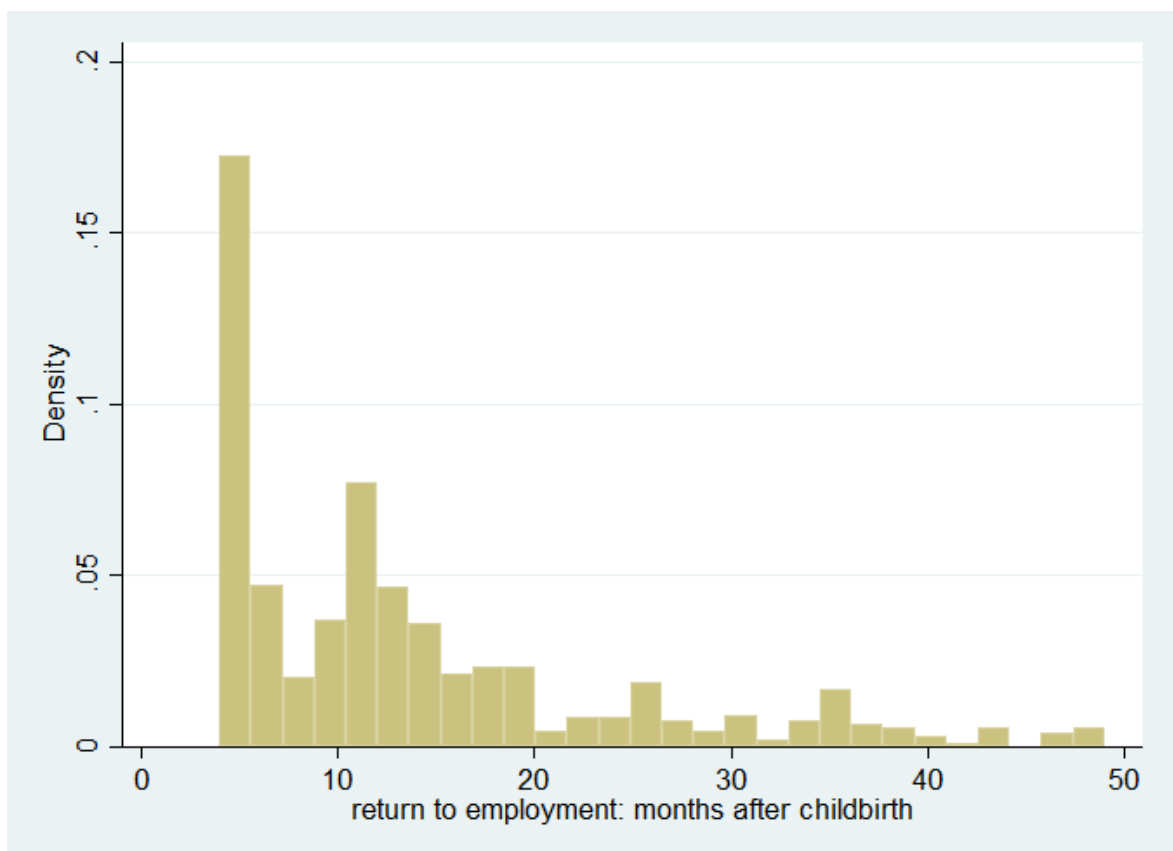

Figure 1: Density of maternity leave spells

Our measure of LOC is based on five items each surveyed in the SOEP in waves 1999, 2005, and 2010. We use the earliest measure available for each individual, i.e., preferably that of $1999 .{ }^{10}$ The LOC items from year 1999 were answered on a 4-point scale (1 "disagree completely" to 4 "agree completely"), while in the 2005 and 2010 surveys the items were answered on 7-point Likert scales (1 "disagree completely" to 7 "agree completely"). To make the scales compatible, we standardize the score of each item and take the average over the five standardized scores. ${ }^{11}$ The higher the LOC index, the more a woman believes she has (internal) control over life events. ${ }^{12}$ Since the LOC items are not collected yearly in the SOEP, we assume that LOC is stable over time. Given previous evidence this seems reasonable. ${ }^{13}$ In section 5.1 we

\footnotetext{
${ }^{10}$ For $68 \%$ of individuals we have information from 1999 , for $27 \%$ from 2005 , and for $5 \%$ our LOC measure stems from 2010. Section (5.1) shows that all results hold using only individuals for whom the 1999 LOC measure is available.

${ }^{11}$ This way of construction the LOC index is also used by Coleman and DeLeire (2003) with the LOC items from the National Educational Longitudinal Study (NELS) and by Cebi (2007) with the LOC items from the National Longitudinal Survey of Youth (NLSY).

${ }^{12}$ Appendix A provides details about the construction of the LOC index as well as about the LOC items.

${ }^{13}$ Cobb-Clark and Schurer (2013) use panel data to show that LOC is relatively stable even during major life events. Personality psychologists widely agree upon mean and rank-order stability of noncognitive skills (or personality traits as they call it) in adulthood (Caspi et al. 2005, Costa Jr and McCrae 1994, Fraley and Roberts 2005, McCrae and Costa 1994, McCrae and Costa Jr 1996, 2003, Roberts and DelVecchio 2000). Heckman et al. (2006) and Coleman and DeLeire (2003) make similar assumptions for data availability reasons.
} 
test whether changes in LOC may be driving our results.

We use a number of socio-economic and demographic control variables: In the main estimations we include the first child's birth cohort (in three-year groups), log of return wage $w_{0}$ - equal to the wage prior to childbirth (we use gross hourly wage, inflation-adjusted to the base year 2011, in Euros), log of other household income $m$ (we use inflation-adjusted net household income net of own labor earnings, in Euros per month), predicted wage growth tendency $\hat{\Delta w}^{\text {TREND }}$ (see section 4.1), and the estimated wage growth penalty $\hat{g}$ (see section 4.2). In extensions of our main specification we include educational attainment (university degree, vocational degree, no professional degree), ISCED categories of educational level, labor market experience prior to first birth in years, mothers' birth cohorts (in groups of five years), partner status (cohabiting), an indicator for the presence of other adults present in the household, regional dummies (16 federal states in Germany), a dummy for East versus West Germany, a dummy variable indicating whether the woman has a second child within three years after the first birth, ${ }^{14}$ the Big Five personality traits, job type (civil servant, self-employed, white-collar, blue-collar), and employment hours (full-time, part-time, marginal employment). Summary statistics of these variables are reported in table 1.

\section{Empirical Strategy}

We want to test whether and how LOC influences return to the labor market. We now present a strategy to estimate the relative importance of our key determinants of maternal return decisions and in particular to assess the channels by which LOC might influence maternal return. The key determinants and channels are deducted from our model above, as derived in section 2.

\footnotetext{
${ }^{14} \mathrm{We}$ tried a number of different specifications to account for having another child within a short period of time; we controlled for having a second or third child within different periods of time and for the spacing between children (in months) and the spacing squared. The main results are always largely the same. See columns (5) and (6) of table 4 , for example.
} 
Table 1: Summary statistics of covariates

\begin{tabular}{|c|c|c|c|c|}
\hline & Mean / Percent & std. dev. & Min. & Max. \\
\hline LOC (higher $=$ more internal) & 0.053 & 0.568 & -1.900 & 1.525 \\
\hline \multicolumn{5}{|l|}{ Spell duration } \\
\hline 4-6 months & $25 \%$ & & & \\
\hline 7-9 months & $9 \%$ & & & \\
\hline $10-12$ months & $13 \%$ & & & \\
\hline $13-18$ months & $18 \%$ & & & \\
\hline 19-24 months & $8 \%$ & & & \\
\hline $25-30$ months & $6 \%$ & & & \\
\hline 31-36 months & $5 \%$ & & & \\
\hline $37-48$ months & $5 \%$ & & & \\
\hline $49-60$ months & $4 \%$ & & & \\
\hline $60+$ months & $7 \%$ & & & \\
\hline \multicolumn{5}{|l|}{ Child birth cohorts } \\
\hline 1992-1994 & $10 \%$ & & & \\
\hline 1995-1997 & $13 \%$ & & & \\
\hline $1998-2000$ & $16 \%$ & & & \\
\hline $2001-2003$ & $16 \%$ & & & \\
\hline 2004-2006 & $17 \%$ & & & \\
\hline $2007-2009$ & $14 \%$ & & & \\
\hline 2010-2012 & $14 \%$ & & & \\
\hline Return wage $w_{0}$ & 54.428 & 22.591 & 4.783 & 205.808 \\
\hline Other household income $m$ & 2410.929 & 1308.446 & 1 & 13929.91 \\
\hline Wage growth tendency $\hat{\Delta w}^{T E N D}$ & 0.102 & 0.189 & -0.02 & 1.704 \\
\hline$\hat{\gamma}$ & 0.026 & 0.013 & 0.008 & 0.050 \\
\hline \multicolumn{5}{|l|}{ Educational degree } \\
\hline University degree & $23 \%$ & & & \\
\hline Vocational degree & $67 \%$ & & & \\
\hline No professional degree & $10 \%$ & & & \\
\hline \multicolumn{5}{|l|}{ ISCED educational levels } \\
\hline general elementary & $9.6 \%$ & & & \\
\hline middle vocational & $45.5 \%$ & & & \\
\hline vocational + high school degr Abitur & $11.3 \%$ & & & \\
\hline higher vocational & $10.5 \%$ & & & \\
\hline higher education & $23.1 \%$ & & & \\
\hline Experience & 7.647 & 4.307 & 0 & 24.6 \\
\hline \multicolumn{5}{|l|}{ Mother birth cohorts } \\
\hline $1955-1959$ & $1 \%$ & & & \\
\hline $1960-1964$ & $5.3 \%$ & & & \\
\hline $1965-1969$ & $22.5 \%$ & & & \\
\hline $1970-1974$ & $28.3 \%$ & & & \\
\hline $1975-1979$ & $26.6 \%$ & & & \\
\hline 1980-1989 & $16.4 \%$ & & & \\
\hline Partner in $\mathrm{HH}$ & $94.5 \%$ & & & \\
\hline Other adults in $\mathrm{HH}$ & $2.7 \%$ & & & \\
\hline East Germany & $21.8 \%$ & & & \\
\hline $2^{\text {nd }}$ child $\mathrm{w} /$ in 3 yrs & $28.9 \%$ & & & \\
\hline \multicolumn{5}{|l|}{ Big Five } \\
\hline Neuroticism & -0.036 & 0.746 & -2.013 & 1.797 \\
\hline Openness & 0.007 & 0.765 & -2.371 & 1.546 \\
\hline Conscientiousness & 0.009 & 0.757 & -3.155 & 0.941 \\
\hline Extraversion & 0.039 & 0.775 & -2.668 & 1.359 \\
\hline Agreeableness & 0.016 & 0.693 & -2.277 & 1.114 \\
\hline \multicolumn{5}{|l|}{ Employment hours } \\
\hline Full-time employment & $84.5 \%$ & & & \\
\hline Part-time employment & $8.5 \%$ & & & \\
\hline Marginal employment & $1.3 \%$ & & & \\
\hline \multicolumn{5}{|l|}{ Job type } \\
\hline Civil servant & $8.7 \%$ & & & \\
\hline Self-employed & $3.7 \%$ & & & \\
\hline White-collar & $69.4 \%$ & & & \\
\hline Blue-collar & $11.2 \%$ & & & \\
\hline
\end{tabular}

Note: $\mathrm{N}=966$ individuals. 
First, we have information about return wages as these are equal to pre-birth wages. Second, in section 4.1 we show how we estimate wage growth tendencies from our pre-birth observations. Third, section 4.2 shows how we assess the influence that maternity leave duration has on post-return wage growth (the wage growth penalty) in different occupations. Fourth, in section 4.3 we explain how we test the role of LOC on return durations via the different channels-i.e., via return wage, wage growth tendency, and differential appreciation of wage growth and wage growth penalty by LOC_-in a simple estimation framework. Finally, in subsection 4.4, we give details of the survival model used for estimation.

\subsection{Individual Wage Growth Tendency}

Following the model presented above, mothers receive wage $w_{0}$ on returning to the labor market. Wage growth after re-entry is modeled in a search framework and the amount of job offers arriving may depend on a number of characteristics including LOC as well as $d$. The model implies that with probability $\lambda($.) mothers receive a wage offer from distribution $F($.$) , such that$ wage growth after return is given by

$$
w_{d+1}-w_{d}=\lambda(d, X) \int_{w_{0}} w^{\prime}-w_{0} d F\left(w^{\prime}\right)
$$

Wage growth depends on factors $X$ including LOC. We assume that these factors are timeconstant and affect wage growth similarly before and after childbirth. We call this the wage growth tendency of a woman. Women with a high wage growth tendency have incentives to return to the labor market quicker than women with a low wage growth tendency because they have higher opportunity costs of staying out of the labor market (see section 2). To empirically assess the influence of wage growth tendency on the return decision, we would not wish to use actual observed wage growth after return (subject to selection issues since $\lambda($.$) also depends on$ d). We thus follow a different strategy to estimate the wage growth tendency of young mothers. We could use observationally similar men or women who have no children; however this group may be specific in other (unobserved) dimensions. In our main specification we thus estimate 
wage growth for women based on their pre-birth wage dynamics. We then predict wage growth tendencies $\left(\hat{\Delta W}^{T R E N D}\right)$ taking into account both observable individual and job characteristics (education, occupation, labor market experience, tenure with the same firm, and region) $x_{i, t}$ as well as an unobserved individual component $\eta_{i}$; in addition, we control for macroeconomic trends $v_{t}$ (year fixed effects). Hence, we estimate women's pre-childbirth earnings dynamics as

$$
\Delta w_{i, t}=\eta_{i}+x_{i, t}^{\prime} \alpha+v_{t}+\varepsilon_{i, t}
$$

where $\Delta w_{i, t}=\log \left(w_{i, t+1}\right)-\log \left(w_{i, t}\right)$. We estimate equation (6) using all periods $t$ prior to pregnancy (at least nine months prior to first childbirth). Note that if LOC influences on-thejob search intensity, this will be part of the individual time-invariant component $\left(\eta_{i}\right)$ of wage growth. ${ }^{15}$ Appendix B provides further details and presents results of the estimation of equation (6). We can now use our estimated parameters $\hat{\eta}, \hat{\alpha}$, and $\hat{v}_{t}$ to predict young mothers' wage growth tendency at the time of childbirth $\left(\hat{\Delta}_{i}{ }^{T R E N D}\right)$ and argue that this is the wage growth that women could expect on returning immediately to the labor market-the following section considers how these wage growth prospects evolve as a function of the duration of maternity leave. Note that this prediction takes into account the fact that women may change their jobs and occupations over the course of their careers. ${ }^{16}$

Our identifying assumption is that the only difference between post- and pre-birth wage growth arises as a result of different maternity leave durations $d$. Then, our estimable equation (6) is a linear (first-order) approximation of wage growth given by expression (5) with $d=0$. Since young mothers do not know the precise rate of their future wage growth, they will base

\footnotetext{
${ }^{15}$ This is true if the role of LOC is constant before and after birth. If, however there was some effect of LOC on wage growth that is specific to post-birth periods, this would not be taken into account.

${ }^{16}$ In predicting counterfactual levels of wage growth for mothers out of the labor market, we could focus only on an individual fixed effect with no other observables. However, pre-birth characteristics may be informative of future wage growth. Being in occupation $j$ at time $t$ on wage growth in time $t+1$ might be associated with a high probability of moving to occupation $k$, where earnings may be higher. For a young mother in occupation $j$ before leaving the labor market to maternity, this may thus be a valuable predictor. The time-varying characteristics we use are subsumed in the vector $x$ in equation (6).
} 
their decisions about $d$ on predictions similar to ours.

Table 1 shows predicted yearly wage growth at the time of first childbirth ${\hat{\Delta w_{i}}}^{\text {TREND }}$. Mean wage growth is $10 \%$ with considerable variance. ${ }^{17}$ Differences in wage growth across occupations is largely consistent with previous findings—e.g., higher for women in technical occupations $(14.8 \%)$ than in health service occupations $(8.8 \%)$.

We also test an on-the-job search channel: if LOC importantly influences job search in employment, it should show up in a higher predicted wage growth tendency (as we include the individual fixed effect in our prediction). However, we find that the predicted wage growth tendency does not depend on LOC (the correlation of $\hat{\eta}$ with LOC is insignificant). Hence, empirically, on-the-job search does not constitute an important channel by which LOC influences mothers' return decisions.

\subsection{Wage Growth Penalty}

We think that the predicted wage growth tendency reflects important individual prospects in wage growth. We now consider by how much wage growth post return is reduced depending on maternity leave duration $d$. Recall that the wage on returning to the labor market is fixed at $w_{0}$ due to German job protection legislation; however, wage growth at return might be reduced depending on leave duration $d$. We denote the extent of wage growth reduction the wage growth penalty. The wage growth penalty varies across occupations. Our hypothesis is that in occupations with a high wage growth penalty, LOC has a larger effect on $d$ than in occupations with a low wage growth penalty. In an extreme case, in an occupation with no wage growth penalty at all, there is no reason for LOC to affect $d$ because there is no cost (no penalty) that needs to be attributed to internally or externally controlled factors (according to internal or external LOC).

\footnotetext{
${ }^{17}$ Expectations of strongly negative wage growth tendencies appear unrealistic, thus we exclude as measurement error rates below $-2 \%$.
} 
To test this channel, we first assess the average wage growth penalty in different occupation categories $j$. We estimate wage growth after return in different occupations as a function of the leave duration $d$ in combination with the predicted wage growth tendency in the same occupation $j$, i.e., we estimate

$$
\Delta w_{i, d}=\left(1-g_{j}(d)\right){\hat{\Delta w_{i}^{T R E N D}}}^{T \iota_{i}}
$$

where $\Delta w_{i, d}=\log \left(w_{i, d+1}\right)-\log \left(w_{i, d}\right)$. The wage growth penalty $g_{j}(d)$ is thus the extent by which wage growth at return is reduced compared to the wage growth tendency. In our estimation we specify a linear penalty function $g_{j}(d)=\gamma_{j} d$. This means that the wage growth penalty for each month of leave is constant. In an occupation with a zero wage growth penalty, we would find $\gamma=0$; i.e., in this occupation, wage growth after return $\left(\Delta w_{i, d}\right)$ corresponds to the predicted wage growth tendency $\left({\hat{\Delta w_{i}}}^{T R E N D}\right)$ plus noise $\left(\iota_{i}\right)$.

Since wage growth post return is estimated as a function of $d$ and $d$ is a choice variable, issues of selection may arise. Most obviously, women with certain unobservable characteristics choose higher $d$ and at the same time have lower wage growth. Our estimation procedure will not be affected if these unobservable characteristics are constant before and after birth and affect wage growth before and after birth equally; this follows from the fact that we estimate wage growth post return as a function of individual wage growth tendency $\left({\hat{\Delta w_{i}}}^{T R E N D}\right)$. Since the wage growth tendency (see the preceding section) is a prediction based on estimated wage growth in pre-birth periods (including individual fixed effects, thus including differences in LOC), it is generated independently of $d$. Only if the unobservable characteristics affect wage growth before birth differently than wage growth after birth, the $\gamma$-coefficients might be estimated with bias. Does this bias our results? Not necessarily, since we are not primarily interested in the predicted effect of $d$ on wage growth post return, $\hat{\gamma}$; rather our aim is to compare wage growth penalties across occupations in order to test whether the effect of LOC on the return decision is moderated by the industry's wage growth penalty - this will depend more on the quality of 
the ranking, less on the absolute values. Therefore, if the distribution of the relevant unobservable characteristics and thus selection into different $d$ was similar in all occupation categories in the way that $\hat{\gamma}_{j}$ relative to $\hat{\gamma}_{k}$ is close to the relation between the true wage growth penalties in occupations $j$ and $k$ for all $j$, selection would not lead to false conclusions in our context. By contrast, if the bias varies strongly between occupation categories, such that the order of wage growth across occupations is affected, we face a problem. We are reassured by the fact that the ranking across different occupations' wage growth penalties seem very plausible (see below, full results are relegated to appendix C).

Finally, another selection problem might occur if $g_{j}(d)$ is importantly non-linear and thus the penalty for a further month of leave depends on the level of $d$. However, we find the simple linear form $g(d)=\gamma d$ performs as well as a quadratic form. We also tested further polynomials and other functional forms such as piece-wise linear transformations. If this function is indeed linear, then the penalty for one more month of leave is constant across $d$. Furthermore, the distribution of the leave duration $d$ seems to be very broad in all occupation categories (cf. figure A2 in appendix C).

Table A5 in appendix $\mathrm{C}$ gives the results of the estimation of equation (7); the distribution of individuals in the eight occupation categories at return is provided in table A6. The estimated wage growth penalties vary between 0.8 and 5 percent per month of maternity leave. The mean wage penalty in our sample is $2.6 \%{ }^{18}$ This implies that a significant proportion of the wage growth tendency is forgone as a result of maternity leave. We now test how these different leave penalties $\hat{\gamma}_{j}$ influence maternal return decisions, especially as moderated by LOC.

\footnotetext{
${ }^{18}$ The rank order of occupations' estimated $\gamma$ seems to be plausible: The occupation category with the highest estimated $\gamma(5 \%)$ is cat. 4 ("merchants of services or associated occupations"). The occupation category with the lowest estimated $\gamma(0.8 \%)$ is cat. 8 ("occupations in transport, regulation, security, writing, translation, librarians, artists, and other service occupations"). The occupation category with the second lowest estimated $\gamma(1.2 \%)$ is cat. 6 ("occupations in health services".
} 


\subsection{Determinants of Returning to Work}

We now estimate determinants of young mothers' return to work as a function of individuals' wage level $w_{0},{ }^{19}$ other household earnings $m$, wage growth tendency $\hat{\Delta w}^{\text {TREND }}$, occupationspecific wage growth penalty $\hat{g}$, and LOC.

LOC influences mothers' maternity leave controlling for the wage level and the wage growth tendency. This means that the effect of LOC on return decisions is not merely an artefact of selection (by LOC) into particular jobs with higher wages or higher wage growth. ${ }^{20}$ If LOC influences maternity leave duration conditional on wage level and wage growth, this may be because mothers with different LOC have different perceptions of human capital depreciation when they are out of employment. By contrast, if we find no evidence for any of these human capital stories, we may conclude that the evidence points towards differences in preference for time spent with young children. The condition for women to return, including multiple channels of LOC influencing return, is

$$
u\left(w_{0}, m\right)+\tilde{E}_{\Delta w}^{L O C}\left[T\left(\Delta w\left(d, w_{0}, m, L O C\right)\right)\right]>u(b(d), m)
$$

Expression (8) implies the following candidates for influencing return decisions:

$$
\left[w_{0, i}, \Delta \hat{w}_{i}^{T R E N D}, L O C_{i}, \Delta \hat{w}_{i}^{T R E N D} \times L O C_{i}, \hat{\gamma}_{j}, \hat{\gamma}_{j} \times L O C_{i}\right]
$$

where the interaction terms show that LOC may influence maternal return decisions by moderating the weight of other determinants.

\footnotetext{
${ }^{19}$ This is the pre-childbirth wage level, but also the wage at which most women can be expected to return to the labor market.

${ }^{20}$ Note that since $d$ may influence wage growth, we use wage growth predictions from pre-maternity periods as explained above in subsection (4.1).
} 


\subsection{The Duration Model}

Since return to the labor market is a binary choice, a linear model would not be appropriate; therefore, we focus on the hazard rate of returning to work, $\theta($.$) , i.e., the probability at any$ duration $d_{i}$ of returning to work given $X_{i}$. We use a mixed proportional hazard framework, such that

$$
\theta(d, X, \eta)=\theta_{0}(d) \exp \left(\beta^{\prime} X\right) \exp (\xi)
$$

where $\theta_{0}(d)$ is the baseline hazard which depends on maternity leave duration $d$ but not on the covariates $X . \beta$ describes the parameter vector to be estimated and $\xi$ is unobserved heterogeneity.

Note three important features of this empirical specification: First, in common with a large literature using survival models, we assume a proportional hazards framework: conditional on $\xi$, absolute differences in the covariates imply proportionate differences in the hazards at each $d .^{21}$

Second, we allow for a flexible semi-parametric form of duration dependence (i.e., the functional form of $\left.\theta_{0}().\right)$ by including interval-specific intercepts. Given that each time interval in the data is of unit length (one month) $)^{22}$ the discrete time hazard can be written as

$$
h(d, X, \xi)=1-\exp \left[-\exp \left(\delta_{k} D_{k}+\beta^{\prime} X+\xi\right)\right]
$$

\footnotetext{
${ }^{21}$ We find descriptive evidence in favor of this assumption by looking at the hazard by different covariates. Merely one determinant, $w_{0}$, appears to change its influence on the hazard. However, conditional on our estimated $\hat{\eta}$ this is no longer the case, consistent with the mixed proportional hazard formulation.

${ }^{22}$ This requires a complementary log-log transformation, see Jenkins (2005, p.41-42).
} 
where $d$ is the number of months after childbirth and $D_{k}$ is an indicator equal to one if month $d$ lies within the $k^{\text {th }}$ interval of maternity duration. ${ }^{23}$ The parameter vector $\delta$ is estimated by the model along with the parameter vector $\beta$.

Third, we include unobserved heterogeneity in a semi-parametric form also, without assuming a specific distribution for the random effect. We assume a discrete distribution of types following Heckman-Singer: ${ }^{24}$ the likelihood contribution of a person with spell length $d$ months is thus

$$
L=\sum_{m}^{M} \pi\left(\xi_{m}\right) L_{\xi}\left(d, X, \xi_{m}\right)
$$

where $M$ is the number of groups of unobserved types ${ }^{25}$ and $\pi$ is the probability of belonging to type $\xi$. Conditional on the belonging to type $\xi$, the likelihood is then

$$
L_{\xi}(d, X, \xi)=\left(\frac{h(d, X, \xi)}{1-h(d, X, \xi)}\right)^{c} \prod_{d^{\prime}=1}^{d}\left[1-h\left(d^{\prime}, X, \xi\right)\right]
$$

where $c$ is the censoring indicator. The parameters $\pi$ and $\xi$ are estimated by the model together with $\beta$ and $\delta$.

\section{Estimation Results}

The main estimation results are reported in table 2. We first show the basic impact of LOC on the timing of labor market return not controlling for the other determinants. Column (1) shows that LOC significantly influences the decision about maternity leave duration. Mothers

\footnotetext{
${ }^{23}$ That is, the model contains one dummy variable for each group of duration: 4-6 months (0-3 are omitted for reasons outlined in section (3)); 7-9 months; 10-15 months; 16-21 months; 22-27 months; 28-33 months, 46-57 months and 58+ months.

${ }^{24}$ The model has also been estimated with a parametrically specified random effect. Gamma distributed and normally distributed $\eta$ were tested, as well as a specification without any random effect. The sign and significance levels of paremter estimates do not change compared to the main results discussed in section (5) below.

${ }^{25}$ We use two mass points in estimation, we also tested specifications with three and four mass points. However Bayesian and Akaike information criteria point to the model with two mass points being suited best.
} 
with more internal LOC have a higher hazard rate of return to employment; i.e., women with a high belief in internal control return to employment significantly earlier than women with a high belief in external control. To illustrate this result, figure 2 plots the hazard functions for two individuals who are equal in all characteristics but LOC. ${ }^{26}$ The solid line in the graph represents a woman with high internal LOC (75th percentile of the LOC score), the dashed line a woman with more external LOC (25th percentile of the LOC score). The solid line runs above the dashed line, illustrating that a person with internal LOC is more likely to return to employment in each period. These differences in hazard rates create differences in the probability of returning to employment. For example, $36 \%$ of women with a high internal LOC score (at the 75th percentile) return to employment twelve months after childbirth; this is more than $16 \%$ higher than for women with a low internal LOC score (at the 25th percentile). Moving from one standard deviation below to one standard deviation above the mean of LOC increases median return time by two months, i.e., by over $13 \%$. The magnitude may seem modest but cumulative knock-on career effects must also be taken into account. Finally, the estimation results that we present next show that this LOC effect masks important effect heterogeneity depending on mothers' occupation: LOC really influences return decisions in occupations with high wage growth penalties.

The step pattern of the graph in figure 2 is a result of our modeling the duration dependency (see section 4). The first clear peak of the hazard function is just after 12 months, suggesting that there is a relatively high probability of returning to employment around the time the child turns one year. The second clear peak is observed in the graph during months 33 to 37 , that is, around the third year after childbirth. This is likely to be a result of the legal right to return to the previous job, which expires after three years. We discuss whether this specific institutional aspect may be driving our results in the following subsection. A smaller peak of the hazard function is observed when the child is six years old, which is the usual school entry age in

\footnotetext{
${ }^{26}$ The graph uses the results of column (4) of table 2 (see below). For the graph all non-binary covariates other than LOC are set to their mean and the child birth cohort is set to the most recent category (i.e., 2010-2012). Considering women with different values in these characteristics would not change the pattern of the graph but only rescale it—due to the proportional hazards feature of the model.
} 
Germany. The irregular pattern of the hazard function over time confirms the importance of allowing for non-parametric duration dependency.

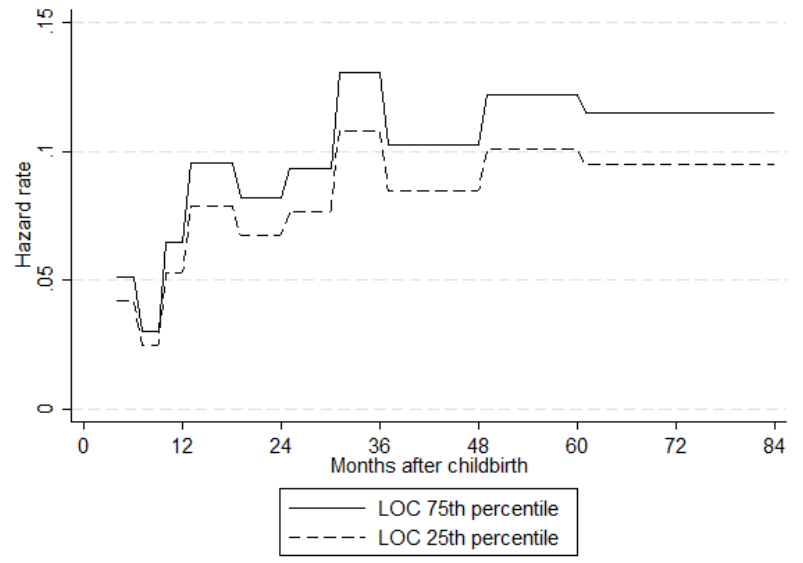

Note: The estimated parameters of model (4) of table 2 are used to calculate the hazard functions. All non-binary covariates other than LOC are set to their mean. We observe the child birth cohort of 2010-2012.

Figure 2: Hazard function by level of LOC 
Table 2: Determinants of return to employment after first childbirth (dependent variable: hazard rate of return), discrete semi-parametric hazard estimation (Heckman-Singer model)

\begin{tabular}{|c|c|c|c|c|c|c|c|c|}
\hline & (1) & (2) & (3) & (4) & (5) & (6) & (7) & (8) \\
\hline Locus of control $L O C$ & $\begin{array}{c}0.300^{* * * *} \\
(0.100)\end{array}$ & $\begin{array}{l}0.287^{*} \\
(0.160)\end{array}$ & $\begin{array}{c}0.215^{* * * *} \\
(0.081)\end{array}$ & $\begin{array}{c}0.302 * * * \\
(0.098)\end{array}$ & $\begin{array}{c}0.298 * * * \\
(0.110)\end{array}$ & $\begin{array}{c}0.256 * * * \\
(0.098)\end{array}$ & $\begin{array}{c}0.244 * * \\
(0.098)\end{array}$ & $\begin{array}{l}-0.112 \\
(0.204)\end{array}$ \\
\hline Return wage $\log \left(w_{0}\right)$ & & $\begin{array}{c}0.203 \\
(0.212)\end{array}$ & $\begin{array}{l}0.174^{*} \\
(0.100)\end{array}$ & $\begin{array}{c}0.389 * * \\
(0.159)\end{array}$ & $\begin{array}{c}0.388 * * \\
(0.160)\end{array}$ & $\begin{array}{l}0.284^{*} \\
(0.152)\end{array}$ & $\begin{array}{l}0.306^{*} \\
(0.162)\end{array}$ & $\begin{array}{l}0.303 * \\
(0.163)\end{array}$ \\
\hline Other household income $\log (m)$ & & & $\begin{array}{c}-0.337 * * * \\
(0.034)\end{array}$ & $\begin{array}{c}-0.436 * * * \\
(0.072)\end{array}$ & $\begin{array}{c}-0.435 * * * \\
(0.076)\end{array}$ & $\begin{array}{c}-0.316^{* * *} \\
(0.055)\end{array}$ & $\begin{array}{c}-0.313 * * * \\
(0.052)\end{array}$ & $\begin{array}{c}-0.312 * * * \\
(0.052)\end{array}$ \\
\hline $\mathrm{W}$ growth tendency $\hat{\Delta w}^{T E N D}$ & & & & $\begin{array}{l}-0.005 \\
(0.253)\end{array}$ & $\begin{array}{l}-0.012 \\
(0.278)\end{array}$ & $\begin{array}{c}0.259 \\
(0.261)\end{array}$ & $\begin{array}{c}0.300 \\
(0.261)\end{array}$ & $\begin{array}{c}0.280 \\
(0.261)\end{array}$ \\
\hline Interaction $\hat{\Delta w}^{T E N D} \times L O C$ & & & & & $\begin{array}{c}0.038 \\
(0.481)\end{array}$ & & & \\
\hline $\mathrm{W}$ growth penalty $\hat{\gamma}_{j}$ & & & & & & & $\begin{array}{l}-6.493 \\
(4.381)\end{array}$ & $\begin{array}{l}-6.635 \\
(4.171)\end{array}$ \\
\hline Interaction $\hat{\gamma}_{j} \times L O C$ & & & & & & & & $\begin{array}{c}13.444 * * \\
(6.461)\end{array}$ \\
\hline Duration dependency & Yes & Yes & Yes & Yes & Yes & Yes & Yes & Yes \\
\hline Child birth cohort & Yes & Yes & Yes & Yes & Yes & Yes & Yes & Yes \\
\hline Constant & $-3.352 * * *$ & $-3.983 * * *$ & $-2.115^{* * *}$ & $-2.103 * * *$ & $-2.106 * * *$ & $-1.473 * * *$ & $-1.318 * * *$ & $-1.215^{* *}$ \\
\hline$z$ & $0.929 * *$ & 0.967 & 0.198 & $0.841 * * *$ & $0.839 * * *$ & $0.489 * *$ & $0.434 * *$ & $0.435 * *$ \\
\hline$p(\mathrm{pct})$ & 0.496 & 0.622 & 2.191 & 0.590 & 0.590 & 0.632 & 0.691 & 0.692 \\
\hline Number of person-spells & 18967 & 18967 & 18967 & 18967 & 18967 & 12262 & 12262 & 12262 \\
\hline Number of persons & 966 & 966 & 966 & 966 & 966 & 748 & 748 & 748 \\
\hline
\end{tabular}

Note: Columns 6-8 are based on a smaller sample since information necessary to estimate wage-growth depreciation terms is not available for all individuals. Standard errors are in parentheses. ${ }^{*} \mathrm{p}<0.10, * * \mathrm{p}<0.05, * * * \mathrm{p}<0.01$. Data source: SOEP 1992-2013, authors' calculations. 
We now test whether the effect of LOC on return is related to material factors. First, column (2) of table 2 introduces return wages $w_{0}$ and finds that these do not have an effect on return as long as other household income $m$ is not included. As soon as the latter is included, we find a positive effect of the wage level on return. This is consistent with the idea that the marginal utility of income (and, given the German tax system, net income) depends on other household income. ${ }^{27}$ Further, we find that the coefficient related to LOC is slightly reduced from .300 in column (1) to .215 in column (3). This suggests that one reason why individuals with more internal LOC return earlier is that they have higher wages. However, even controlling for the wage level, LOC still has a significantly positive effect on leave duration.

In a second step, we introduce workers' predicted wage growth tendency $\hat{\Delta w}^{\text {TREND }}$ (from section 4.1) in column (4). It does not appear to influence return decisions; i.e., wage growth tendencies seem not to be a channel by which LOC influences return decisions. Further, the interaction between wage growth tendency and LOC in column (5) is not a significant determinant of return decisions either; put differently, the effect of wage growth tendency is not differentially appreciated depending on LOC.

Third, column (7) shows that the average wage penalty in an occupation does not significantly affect the return hazard. This suggests that women do not self-select into occupations with a certain $\hat{g}_{j}$ according to their planned $d$. However, introducing the interaction between $\hat{g}_{j}$ and LOC reveals that wage growth penalties do play a role for mothers' return decision for individuals with high LOC scores. In fact, this appears to be the main channel by which LOC influences maternal return decisions: the direct, unconditional measure of LOC is now no longer significant. Given that we have fewer data-points on occupational categories for these analyses, we also test our benchmark results using this smaller sample to ensure that any results are related to sample selection. Column (6) shows that estimates are similar in this sample.

\footnotetext{
${ }^{27}$ We tested a number of functional forms for this relationship, including own wage in levels and logs and relative to total household wage and find the results of column (4) to be largely robust.
} 
We next turn to non-wage dimensions of human capital. We find no evidence that the introduction of education variables influences the effect of LOC on return decisions, as both the introduction of simple dummies for formal education (in column (2) of table 3) as well as more detailed ISCED education categories (in column (3) of table 3) confirm. While there may be a small effect of experience on return (controlling for wage and wage growth), the effect is only significant at $10 \%$ (column (4) of table 3 ). When we introduce maternal birth cohorts (thus implicitly controlling for mothers' age at first childbirth) on top of child birth cohorts , the results change very little, as can be seen from column (5) of table 3.

We include a range of further covariates to test the sensitivity of our results. Among those covariates we find regional dummies to have most significance (see column (2)-(4) of table 4): living in East Germany is related to a quicker return-a finding that may relate both to differences in child-care provision and social norms. Cohabiting with a partner and the presence of another adult living in the same household do not appear to affect return to employment (columns (6) and (7) of table 3) conditional on household income. 
Table 3: Determinants of return to employment after first childbirth (dependent variable: hazard rate of return), discrete semi-parametric hazard estimation (Heckman-Singer model) — with further covariates (I)

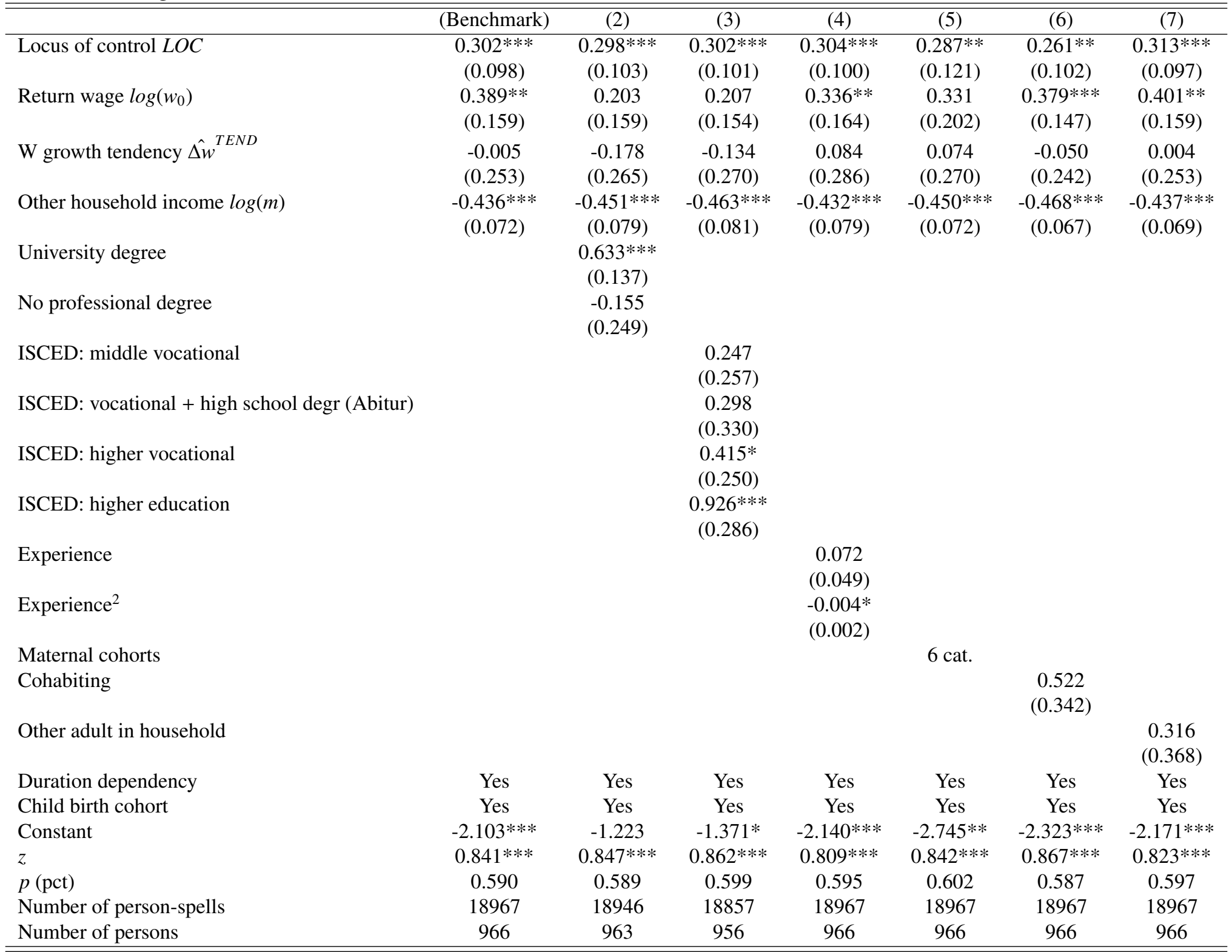

Note: Standard errors are in parentheses. * $\mathrm{p}<0.10$, ** $\mathrm{p}<0.05, * * * \mathrm{p}<0.01$. Data source: SOEP 1992-2013, authors' calculations. 
Table 4: Determinants of return to employment after first childbirth (dependent variable: hazard rate of return), discrete semi-parametric hazard estimation (Heckman-Singer model) — with further covariates (II)

\begin{tabular}{|c|c|c|c|c|c|c|}
\hline & (Benchmark) & $(2)$ & (3) & (4) & (5) & (6) \\
\hline Locus of control $L O C$ & $\begin{array}{c}0.302 * * * \\
(0.098)\end{array}$ & $\begin{array}{c}0.195 * * * \\
(0.072)\end{array}$ & $\begin{array}{c}0.195 * * * \\
(0.072)\end{array}$ & $\begin{array}{c}0.194 * * * \\
(0.073)\end{array}$ & $\begin{array}{c}0.305^{* * *} \\
(0.098)\end{array}$ & $\begin{array}{c}0.294 * * * \\
(0.083)\end{array}$ \\
\hline Return wage $\log \left(w_{0}\right)$ & $\begin{array}{c}0.389^{* *} \\
(0.159)\end{array}$ & $\begin{array}{c}0.237 * * \\
(0.105)\end{array}$ & $\begin{array}{c}0.238^{* *} \\
(0.103)\end{array}$ & $\begin{array}{c}0.242 * * \\
(0.100)\end{array}$ & $\begin{array}{c}0.391 * * \\
(0.161)\end{array}$ & $\begin{array}{l}0.180^{*} \\
(0.097)\end{array}$ \\
\hline $\mathrm{W}$ growth tendency $\hat{\Delta w}^{T E N D}$ & $\begin{array}{l}-0.005 \\
(0.253)\end{array}$ & $\begin{array}{l}-0.346 \\
(0.238)\end{array}$ & $\begin{array}{l}-0.335 \\
(0.237)\end{array}$ & $\begin{array}{c}-0.243 \\
(0.233)\end{array}$ & $\begin{array}{l}-0.004 \\
(0.253)\end{array}$ & $\begin{array}{l}-0.262 \\
(0.263)\end{array}$ \\
\hline Other household income $\log (m)$ & $\begin{array}{c}-0.436 * * * \\
(0.072)\end{array}$ & $\begin{array}{c}-0.342 * * * \\
(0.035)\end{array}$ & $\begin{array}{c}-0.341 * * * \\
(0.039)\end{array}$ & $\begin{array}{c}-0.334 * * * \\
(0.034)\end{array}$ & $\begin{array}{c}-0.433 * * * \\
(0.075)\end{array}$ & $\begin{array}{c}-0.334 * * * \\
(0.032)\end{array}$ \\
\hline Regional dummies & & 16 cat. & 16 cat. & & & \\
\hline Other adult in household & & & $\begin{array}{l}0.674 * \\
(0.371)\end{array}$ & $\begin{array}{c}0.542 \\
(0.342)\end{array}$ & & \\
\hline Cohabiting & & & $\begin{array}{c}0.282 \\
(0.275)\end{array}$ & $\begin{array}{c}0.223 \\
(0.206)\end{array}$ & & \\
\hline East Germany & & & & $\begin{array}{c}0.243^{* * *} \\
(0.100)\end{array}$ & & \\
\hline Second child within 3 yrs & & & & & $\begin{array}{l}-0.076 \\
(0.137)\end{array}$ & $\begin{array}{c}-0.179 \\
(0.112)\end{array}$ \\
\hline Interaction second child $\times L O C$ & & & & & & $\begin{array}{l}-0.252 \\
(0.161)\end{array}$ \\
\hline Duration dependency & Yes & Yes & Yes & Yes & Yes & Yes \\
\hline Child birth cohort & Yes & Yes & Yes & Yes & Yes & Yes \\
\hline Constant & $-2.103 * * *$ & $-1.855 * * *$ & $-2.164 * * *$ & $-2.626 * * *$ & $-2.115 * * *$ & $-2.023 * * *$ \\
\hline$z$ & $0.841 * * *$ & 0.175 & $0.164 * * *$ & $0.161 * * *$ & $0.849 * * *$ & $0.169 * * *$ \\
\hline$p(\mathrm{pct})$ & 0.590 & 0.920 & 0.934 & 0.928 & 0.581 & 0.926 \\
\hline Number of person-spells & 18967 & 18967 & 18967 & 18967 & 18929 & 18929 \\
\hline Number of persons & 966 & 966 & 966 & 966 & 960 & 960 \\
\hline
\end{tabular}
calculations. 
Finally, we find evidence of significant unobserved heterogeneity in most specifications. Since our estimation is based on random effects, these are not treated as individual effects to be estimated but as nuisance parameters that are integrated out. To gain an understanding of the dimensions which the random effects are covering, ${ }^{28}$ we recover estimated probabilities by considering the posterior distribution of types after convergence in our benchmark specification (see table 2). The only significant correlate of type probabilities we find is the East dummy, viz., some regional dummies if we include one for each region. Most obviously, this may be related to differences in child-care provision across different regions.

\subsection{Robustness Tests}

In this subsection, we discuss a number of challenges to our findings. A first concern refers to the endogeneity of LOC with childbirth. We assume that LOC is constant over time for each individual, in line with previous research. Our LOC measure comes from different years (1999, 2005, and 2010), for some women this is prior to having the first child, while for others it is after having the first child. If LOC evolves over time, certain characteristics of a newborn child (e.g., poor health) might cause a mother to adopt a more external LOC and, at the same time, extend her leave duration. To test the robustness of our results, we first create a dummy for women who had their first child after their LOC was measured. We find this indicator not to be significantly correlated with LOC; the same is true if we regress LOC on this indicator including further covariates such as children's birth cohorts. This provides first evidence for the robustness of our results. In a second step we carry out the following robustness tests of our main estimations: First we restrict the sample to mothers of children born after LOC is surveyed (column (2) of table 5). To make the sample even more homogeneous, second, we restrict the sample to mothers for whom LOC is measured in 1999 (column (3) of table 5). Third, we re-

\footnotetext{
${ }^{28} \mathrm{We}$ are cautious about interpreting the predicted probabilities. Heckman and Singer (1984) note that their estimation method "recovers the structural parameters of the underlying models very well but does not accurately estimate the distribution of unobservables even in very large samples." If we had multiple spells per individual, we might have more confidence in the identification of these parameters (for a discussion on the benefits of multi-spell data, see van den Berg (2001)).
} 
strict the sample to mothers for whom LOC is measured in 1999 and who have their first child after LOC is measured (i.e., after 1999) (column (4) of table 5). The results are robust to all these restrictions. This suggests that our main result is unlikely to be affected by LOC evolving as a result of childbirth.

A second concern relates to LOC picking up other noncognitive skills that might be the true reason for a delayed or quicker return to work. We thus now control for important other noncognitive skills in order to minimize the probability of LOC picking up other skills or traits. We focus on the Big Five personality traits identified in personality psychology: neuroticism, openness to experience, conscientiousness, extraversion, and agreeableness (John and Srivastava 1999, McCrae and Costa Jr 1996, 1999). The Big Five concept is among the best-established models in personality psychology and widely used in empirical research (Caspi et al. 2005). Column (5) of table 5 reports the results of including these five dimensions in the benchmark specification. ${ }^{29} \mathrm{We}$ find that extraversion is associated with faster return to the labor market. We note that the effect of LOC on the outcome persists-in fact, the magnitude has increased. The effect of LOC on the outcome seems not to be due to LOC picking up other personality traits. Finally, LOC could pick up the effect of cognitive ability, which is likely correlated. However, the most important channel of cognitive skills affecting mothers' return decision is predicted to go through their reward on the labor market, and should be reflected in wage levels and growth. We have demonstrated that LOC influences return conditional on wage level and growth, arguing that LOC operates by different appreciation of wage growth penalties.

\footnotetext{
${ }^{29}$ The SOEP wave 2005 provides a set of fifteen items of the big five-three for each of the five dimensionsthat were answered on a 7-point Likert scale. We use standardized mean answer scores as indicators for the five variables. For more information on the implementation of the Big Five traits in the SOEP survey as well as on the reliability and validity, see Dehne and Schupp (2007).
} 
Table 5: Determinants of return to employment after first childbirth (dependent variable: hazard rate of return), discrete semi-parametric hazard estimation (Heckman-Singer model) — robustness tests

\begin{tabular}{|c|c|c|c|c|c|c|c|}
\hline & (Benchmark) & (2) & (3) & (4) & $(5)$ & (6) & (7) \\
\hline Locus of control $L O C$ & $\begin{array}{c}0.302 * * * \\
(0.098)\end{array}$ & $\begin{array}{l}0.265^{*} \\
(0.142)\end{array}$ & & & $\begin{array}{c}0.396^{* * * *} \\
(0.115)\end{array}$ & $\begin{array}{c}0.283 * * \\
(0.111)\end{array}$ & $\begin{array}{c}0.270 * * \\
(0.106)\end{array}$ \\
\hline Locus of control LOC from 1999 & & & $\begin{array}{c}0.343 * * * \\
(0.102)\end{array}$ & $\begin{array}{c}0.365^{* *} \\
(0.145)\end{array}$ & & & \\
\hline Return wage $\log \left(w_{0}\right)$ & $\begin{array}{c}0.389 * * \\
(0.159)\end{array}$ & $\begin{array}{c}0.386 \\
(0.249)\end{array}$ & $\begin{array}{c}0.428 * * \\
(0.175)\end{array}$ & $\begin{array}{c}0.375 \\
(0.257)\end{array}$ & $\begin{array}{c}0.365^{* *} \\
(0.165)\end{array}$ & $\begin{array}{c}0.409 * * \\
(0.170)\end{array}$ & $\begin{array}{c}0.127 \\
(0.149)\end{array}$ \\
\hline $\mathrm{W}$ growth tendency $\hat{\Delta w}^{T E N D}$ & $\begin{array}{c}-0.005 \\
(0.253)\end{array}$ & $\begin{array}{c}-0.294 \\
(0.386)\end{array}$ & $\begin{array}{c}0.173 \\
(0.276)\end{array}$ & $\begin{array}{l}-0.247 \\
(0.342)\end{array}$ & $\begin{array}{c}0.182 \\
(0.321)\end{array}$ & $\begin{array}{c}-0.168 \\
(0.299)\end{array}$ & $\begin{array}{c}-0.533 \\
(0.401)\end{array}$ \\
\hline Other household income $\log (m)$ & $\begin{array}{c}-0.436 * * * \\
(0.072)\end{array}$ & $\begin{array}{c}-0.615 * * * \\
(0.236)\end{array}$ & $\begin{array}{c}-0.412 * * * \\
(0.073)\end{array}$ & $\begin{array}{c}-0.592 * * \\
(0.238)\end{array}$ & $\begin{array}{c}-0.447 * * * \\
(0.064)\end{array}$ & $\begin{array}{c}-0.455 * * * \\
(0.069)\end{array}$ & $\begin{array}{c}-0.329 * * * \\
(0.050)\end{array}$ \\
\hline Neuroticism & & & & & $\begin{array}{c}0.109 \\
(0.088)\end{array}$ & & \\
\hline Openness & & & & & $\begin{array}{l}-0.004 \\
(0.105)\end{array}$ & & \\
\hline Conscientiousness & & & & & $\begin{array}{c}0.042 \\
(0.090)\end{array}$ & & \\
\hline Extraversion & & & & & $\begin{array}{c}0.241 * * * \\
(0.087)\end{array}$ & & \\
\hline Agreeableness & & & & & $\begin{array}{l}-0.033 \\
(0.098)\end{array}$ & & \\
\hline Part-time employment & & & & & & $\begin{array}{l}-0.282 \\
(0.235)\end{array}$ & \\
\hline Marginal employment & & & & & & $\begin{array}{c}1.010 \\
(0.814)\end{array}$ & \\
\hline Civil servant & & & & & & $\begin{array}{c}0.392 * * \\
(0.184)\end{array}$ & \\
\hline Self-employed & & & & & & $\begin{array}{c}1.591 * * * \\
(0.419)\end{array}$ & \\
\hline Blue-collar worker & & & & & & $\begin{array}{c}0.100 \\
(0.200)\end{array}$ & \\
\hline Duration dependency & Yes & Yes & Yes & Yes & Yes & Yes & Yes \\
\hline Child birth cohort & Yes & Yes & Yes & Yes & Yes & Yes & Yes \\
\hline Constant & $-2.103 * * *$ & 2.192 & $-2.346 * * *$ & 2.246 & $-1.736 * *$ & $-2.054 * * *$ & $-2.428 * * *$ \\
\hline$z$ & $0.841 * * *$ & $1.215^{* * *}$ & $0.937 * * *$ & $1.496 * * *$ & $0.652 * * *$ & $0.914 * * *$ & $0.171 * * *$ \\
\hline$p(\mathrm{pct})$ & 0.590 & 0.631 & 0.548 & 0.586 & 0.701 & 0.582 & 0.942 \\
\hline Number of person-spells & 18967 & 7394 & 15309 & 5614 & 16547 & 18967 & 6944 \\
\hline
\end{tabular}


A third major concern could be that women with certain LOC select themselves into specific job types—e.g., civil service or self-employment—or choose especially family friendly employment hours-like part-time schedules—and that these job types and employment hours are, at the same time, more compatible with a longer or shorter leave. If this is the case, then LOC would not directly affect the decision to return to employment but rather indirectly through the choice of the job type and employment hours prior to childbirth. To check this channel, we introduce a set of variables characterizing the job type occupied prior to childbirth: civil servant, self-employed, blue collar worker, and white collar worker (reference category). Additionally, working hours categories are introduced: we differentiate part-time and marginal employment (tax-free minijobs) from full-time employment. The results with the additional covariates are reported in column (6) of table 5. Although it emerges that some of the variables have additional predictive power-not surprisingly, self-employed women appear to return to employment more quickly - the main results remain stable. If anything, the magnitude of the coefficient on LOC has again increased, suggesting that it is not via choice of job type that LOC influences maternity leave durations.

Fourth, we may be interested to assess to what extent the result is driven by mothers' decision to have a second child. Differences in LOC may relate to different preferences about child spacing rather than labor supply. If individuals (with different LOC levels) have the same total number of children, our results could be consistent with the same life-time labor supply despite later returns of mothers who have their children with shorter intervals. We address this concern in two ways: First, we focus on women who are observed to only have one child in the sample, yielding a sample of 6944 spells from 481 women. ${ }^{30}$ Column (7) in table 5 shows that the effect of LOC remains largely unchanged in this smaller sample. Second, we find similar patterns when we censor women at the moment they become pregnant with their second child. ${ }^{31}$ Finally, note that average child spacing in Germany is over 3 years, whereas median return to the labor market occurs after around 10 months in our data. These all point against a strong influence of

\footnotetext{
${ }^{30}$ We attempted to restrict the sample to women who have completed their fertility (age 40 plus), but many women are younger at the last observation in the sample, yielding a too small sample for estimation.

${ }^{31}$ Results are available on request.
} 
second children on return decisions after the first child.

Fifth, our model is based on labor supply decisions driving return. This makes sense for returns to employment within the institutional framework of job protection. Within this period, we are confident that the most important effects will be labor-supply driven. The loss of job protection at 36 months of maternity leave is an important labor demand effect: Mothers are no longer guaranteed their previous wage but may need to search for a job. If this institutional feature is an important determinant of maternal return, we should observe a significant effect of this threshold on maternal returns. Figure (1) shows the density of (completed) maternity leave durations. We find, first, that only a small fraction—less than $15 \%$ - of maternal returns occur after 36 months. Second, there appears to be some bunching at the threshold, i.e., a positive mass of individuals choose exactly 36 months. We thus test the importance of the other determinants of the model in explaining durations by adding a specific shifter for return at around 36 months. ${ }^{32}$ While the hazard at this specific date is indeed discretely higher than for other periods controlling for all the other determinants, ${ }^{33}$ controlling for this specific group does not alter the magnitude or significance of LOC in return decisions. ${ }^{34}$ Furthermore, it is not the case that mothers react to the institutional set-up differentially according to their LOC. Finally, conditional on this institutional threshold, we still find that the main effect of LOC runs by a differential appreciation of the wage growth penalty. We thus believe that while labor demand constraints resulting from differential job protection rules are an important part of return decisions, our results are robust to taking this aspect into account.

\footnotetext{
${ }^{32}$ After inspection of the data, we include individuals who report 37 months of maternity leave in this category.

${ }^{33}$ We believe this bunching is not a function of a sudden change in underlying preferences of mothers. Next to the labor demand effect discussed here, the difference could also stem from effects of child-care provision at age three.

${ }^{34}$ The results of this robustness check are available on request.
} 


\section{Conclusion}

The present study investigates the effect of locus of control (LOC) on the duration of mothers' leave after first childbirth. Using data from the German Socio-Economic Panel Study (SOEP) we find that women with a more internal LOC return to employment faster. We show that this is not mainly a result of differences in wage levels or wage growth rates. Rather, we find that the main reason that individuals with more external LOC return later is that they react less to what we call wage growth penalties. These are estimated reductions in mothers' wage growth prospects-reducing wage growth more the longer women stay out of the labor market after childbirth. The paper contributes to understanding the impact that LOC has on important economic outcomes.

First, if mothers with external LOC do not fully take into account the effects of long labor market breaks, they will stay out of the labor market for too long. This may cause large career costs for mothers with external LOC.

Second, our results indicate that changes in financial incentives influence LOC-external mothers' return decisions less strongly if they accrue in the future and are seen as uncertain. This insensitivity is relevant to policy: For example, subsidizing child-care costs financed by higher taxation after return to work could be welfare-enhancing. Also, this lack of sensitivity means there will be less negative moral hazard issues associated with transfers later in life. Consider two reforms that were instituted in Germany: (i) providing pensioners a minimum level of state pension; (ii) increasing pension payments to mothers with long periods out of the labor market (Mütterrente). Both reduce incentives to work for individuals with low contributions. If pension payments are seen as uncertain, women with external LOC will reduce their labor supply less as a reaction to the more generous new pension rules. This may then suggest an overall smaller reaction of female labor supply to pension changes-consistent with early evidence of the Mütterrente. 
Third, noncognitive skills such as LOC—whilst relatively stable across adult life—are not predetermined but develop during childhood and adolescence (Cunha and Heckman 2007, 2008). Family and education can importantly determine non-cognitive skills. Policies which foster internal LOC may especially benefit girls by fostering their long-term career prospects. 


\section{Appendix A}

\section{The Construction of the LOC Variable and Factor Analysis}

LOC is typically conceived as a unidimensional concept with "internal" and "external" as opposite poles of the same dimension (see, e.g., Piatek and Pinger 2015, Caliendo et al. 2015, Coleman and DeLeire 2003, Cebi 2007). LOC describes the extent to which individuals believe they can determine events in their own lives (internal) as opposed to feeling dependent on factors that are outside of their control (external). The unidimensional LOC index we use in our estimations is based on five items surveyed in the SOEP; the items are given in table A1. We standardize the score of each item and take the average over the five standardized scores. All items but the first are reverse coded such that a higher LOC index reflects a more internal LOC.

Running an exploratory factor analysis over the five items in our sample confirms the assumption of one single latent factor behind the items: only the eigenvalue of factor 1 is larger than one; the others are clearly below. The relative signs of the factor loadings correspond to the way the items are included in the LOC score (i.e., item 1 is reverse compared to the other items). The results of the factor analysis are given in table A1.

\section{Discussion of Alternative Versions of Constructing a LOC Variable}

In the SOEP, the five LOC items are part of a 10-item battery that are related to LOC but that do not all reflect the original concept of LOC by Rotter (1966). Table A2 gives the 10 items (the five items used in our LOC score are in bold). We excluded five items from our main LOC index for the following reasons: Item Q2 (Compared to other people, I have not achieved what I deserve) does not reflect internal versus external LOC but rather measures an individuals sense of fairness (Weinhardt and Schupp 2011, Piatek and Pinger 2015). Item Q4 (If a person is socially or politically active, he/she can have an effect on social conditions) rather measures an individuals degree of social involvement (Weinhardt and Schupp 2011, Piatek and Pinger 
Table A1: Factor analysis with five LOC items

\begin{tabular}{|c|c|c|}
\hline $\begin{array}{l}\text { Q1 How my life goes depends on me (Wie mein Leben verläuft, } \\
\text { hängt von mir selbst ab). }\end{array}$ & $\begin{array}{c}\text { Factor1 } \\
-.2598271\end{array}$ & $\begin{array}{l}\text { Factor2 } \\
.0660362\end{array}$ \\
\hline $\begin{array}{l}\text { Q3 What a person achieves in life is above all a question of fate or } \\
\text { luck (Was man im Leben erreicht, ist in erster Linie eine Frage von } \\
\text { Schicksal oder Glück). }\end{array}$ & .407111 & .0884543 \\
\hline $\begin{array}{l}\text { Q5 I frequently have the experience that other people have a con- } \\
\text { trolling influence over my life (Ich mache häufig die Erfahrung, } \\
\text { dass andere über mein Leben bestimmen). }\end{array}$ & .575017 & -.0324929 \\
\hline $\begin{array}{l}\text { Q8 The opportunities that I have in life are determined by the social } \\
\text { conditions (Welche Möglichkeiten ich im Leben habe, wird von } \\
\text { den sozialen Umständen bestimmt). }\end{array}$ & .3125508 & .1449504 \\
\hline $\begin{array}{l}\text { Q10 I have little control over the things that happen in my life } \\
\text { (Ich habe wenig Kontrolle über die Dinge, die in meinem Leben } \\
\text { passieren). }\end{array}$ & .6047107 & -.0751981 \\
\hline
\end{tabular}

\section{Eigenvalue}

Factor 1

1.027257

Factor 2

.0399061

Factor 3

$-.0181629$

Factor 4

$-.0878149$

Factor 5

$-.2522844$

$\mathrm{N}=966$ individuals. 
2015). Item Q6 (One has to work hard in order to succeed) measures the degree to which someone attributes success to effort, which would be part of an internal LOC. However, for respondents who disagree with item Q6's statement it is unclear whether they attribute success to stable skills (which would also be part of an internal LOC) or to forces outside of themselves (which would be part of an external LOC). Therefore, this item is inappropriate for measuring internal versus external LOC. Item Q7 (If I run up against difficulties in life, I often doubt my own abilities) displays a similar problem as item Q6; for respondents who disagree with the item's statement it is unclear whether they attribute difficulties to the lack of own effort (which would also be part of an internal LOC) or whether they attribute difficulties rather to forces outside of themselves (which would be part of an external LOC). Item Q9 (Innate abilities are more important than any efforts one can make) explicitly measures the weight a person places on effort versus skills—-while both would be subsumed under an internal LOC according to Rotter (1966). For these reasons, we exclude these five items from our main LOC index. The five items we do include in our LOC index (the items printed bold) are appropriate for measuring the unidimensional trait of internal versus external LOC. These items correspond to the LOC items in the National Educational Longitudinal Study (NELS), which has been used e.g., by Cebi (2007), Coleman and DeLeire (2003) and Heckman et al. (2006). The five inappropriate SOEP items have no corresponding items in the NELS.

Caliendo et al. (2015) construct a similar LOC index as we do but they include nine out of the ten SOEP items, dropping only item Q4 (and reverse coding items Q2, Q3, Q5, Q7, Q8, and Q10). We run a robustness test with a LOC index using their items; the main results of the paper do not change (see column (2) of table A3). Piatek and Pinger (2015) use only items Q3, Q5, Q7, Q8, and Q10, i.e., they use similar items as we do but substitute Q1 by Q7. We run a robustness test with a LOC index using the items selected by Piatek and Pinger (2015); the results of our paper do not change (see column (3) of table A3). 
Running a factor analysis over the ten items confirms the strength of the first latent factor. The results of the factor analysis are given in table A2. The factor loadings suggest dropping items Q4, Q6, and Q9 which do not load on the latent factor. A similar result of a factor analysis of the LOC-items from the SOEP is found for example by Specht et al. (2013). ${ }^{35}$ Since the factor analysis does not imply to exclude items Q2 and Q7, we do another robustness test: even though items Q2 and Q7 do not fit into the original one-dimensional concept of LOC as argued above, we include these items in the LOC index (reverse coding items Q2, Q3, Q5, Q7, Q8, and Q10); our main results are robust to this modification (see column (4) of table A3).

A further robustness test is conducted employing a factor score of LOC weighting the items according to the factor analysis reported in table A1 (similar to Piatek and Pinger (2015)) instead of weighting all component items of the LOC index equally. The results are reported in column (5) of table A3. Our main results are robust to using this alternative LOC-score.

${ }^{35}$ They also drop items Q4, Q6, and Q9 ex-ante, using only seven of the ten items. 


\begin{tabular}{|c|c|c|c|}
\hline & Factor 1 & Factor 2 & Factor 3 \\
\hline $\begin{array}{l}\text { Q1 How my life goes depends on me (Wie mein Leben } \\
\text { verläuft, hängt von mir selbst ab). }\end{array}$ & -.2244663 & .3317205 & .1397904 \\
\hline $\begin{array}{l}\text { Q2 Compared to other people, I have not achieved what } \\
\text { I deserve (Im Vergleich mit anderen habe ich nicht das } \\
\text { erreicht, was ich verdient habe). }\end{array}$ & .4855427 & .0709979 & -.0730634 \\
\hline $\begin{array}{l}\text { Q3 What a person achieves in life is above all a ques- } \\
\text { tion of fate or luck (Was man im Leben erreicht, ist in } \\
\text { erster Linie eine Frage von Schicksal oder Glück). }\end{array}$ & .405968 & .0981938 & -.1910283 \\
\hline $\begin{array}{l}\text { Q4 If a person is socially or politically active, he/she } \\
\text { can have an effect on social conditions (Wenn man sich } \\
\text { sozial oder politisch engagiert, kann man die sozialen } \\
\text { Verhältnisse beeinflussen). }\end{array}$ & .0963083 & .0461371 & .1972745 \\
\hline $\begin{array}{l}\text { Q5 I frequently have the experience that other people } \\
\text { have a controlling influence over my life (Ich mache } \\
\text { häufig die Erfahrung, dass andere über mein Leben } \\
\text { bestimmen). }\end{array}$ & .6344261 & .0101093 & 1099268 \\
\hline $\begin{array}{l}\text { Q6 One has to work hard in order to succeed (Erfolg muss } \\
\text { man sich hart erarbeiten). }\end{array}$ & .0317271 & .3904663 & -.0564504 \\
\hline $\begin{array}{l}\text { Q7 If I run up against difficulties in life, I often doubt my } \\
\text { own abilities (Wenn ich im Leben auf Schwierigkeiten } \\
\text { stoße, zweifle ich oft an meinen Fähigkeiten). }\end{array}$ & .4587426 & -.0118316 & .1196966 \\
\hline $\begin{array}{l}\text { Q8 The opportunities that I have in life are deter- } \\
\text { mined by the social conditions (Welche Möglichkeiten } \\
\text { ich im Leben habe, wird von den sozialen Umständen } \\
\text { bestimmt). }\end{array}$ & .3267092 & .1440986 & -.0532071 \\
\hline $\begin{array}{l}\text { Q9 Innate abilities are more important than any efforts } \\
\text { one can make (Wichtiger als alle Anstrengungen sind die } \\
\text { Fähigkeiten, die man mitbringt). }\end{array}$ & .1013728 & .3544741 & .0105248 \\
\hline $\begin{array}{l}\text { Q10 I have little control over the things that happen } \\
\text { in my life (Ich habe wenig Kontrolle über die Dinge, } \\
\text { die in meinem Leben passieren). }\end{array}$ & .6018275 & -.1673338 & .0313426 \\
\hline
\end{tabular}

\begin{tabular}{lc}
\hline & Eigenvalue \\
Factor 1 & 1.553382 \\
Factor 2 & .4539728 \\
Factor 3 & .1338106 \\
Factor 4 & .0469835 \\
Factor 5 & .0194704 \\
Factor 6 & -.088547 \\
Factor 7 & -.1033458 \\
Factor 8 & -.1480346 \\
Factor 9 & -.2053569 \\
Factor 10 & -.2317325 \\
\hline \hline
\end{tabular}

$\mathrm{N}=964$ individuals. 
Table A3: Determinants of return to employment after first childbirth (dependent variable: hazard rate of return), discrete semi-parametric hazard estimation (Heckman-Singer model) - robustness tests w.r.t. the construction of the LOC variable

\begin{tabular}{|c|c|c|c|c|c|}
\hline & (Benchmark) & (2) & (3) & (4) & $(5)$ \\
\hline Locus of control $L O C$ & $\begin{array}{c}0.302 * * * \\
(0.098)\end{array}$ & & & & \\
\hline LOC Caliendo et al. (2015) & & $\begin{array}{c}0.047 * * * \\
(0.013)\end{array}$ & & & \\
\hline LOC Piatek and Pinger (2015) & & & $\begin{array}{c}0.039 * * * \\
(0.014)\end{array}$ & & \\
\hline$L O C$ incl Q2 + Q7 & & & & $\begin{array}{c}0.260 * * * \\
(0.072)\end{array}$ & \\
\hline$L O C$ factor score & & & & & $\begin{array}{c}-0.137 * * * \\
(0.045)\end{array}$ \\
\hline Return wage $\log \left(w_{0}\right)$ & $\begin{array}{c}0.389 * * \\
(0.159)\end{array}$ & $\begin{array}{c}0.414 * * * \\
(0.153)\end{array}$ & $\begin{array}{l}0.166^{*} \\
(0.098)\end{array}$ & $\begin{array}{c}0.387 * * \\
(0.167)\end{array}$ & $\begin{array}{c}0.382 * * \\
(0.164)\end{array}$ \\
\hline $\mathrm{W}$ growth tendency $\hat{\Delta w}^{T E N D}$ & $\begin{array}{l}-0.005 \\
(0.253)\end{array}$ & $\begin{array}{c}0.018 \\
(0.255)\end{array}$ & $\begin{array}{l}-0.195 \\
(0.253)\end{array}$ & $\begin{array}{c}0.011 \\
(0.253)\end{array}$ & $\begin{array}{c}-0.008 \\
(0.251)\end{array}$ \\
\hline Other household income $\log (m)$ & $\begin{array}{c}-0.436 * * * \\
(0.072)\end{array}$ & $\begin{array}{c}-0.439 * * * \\
(0.069)\end{array}$ & $\begin{array}{c}-0.339 * * * \\
(0.032)\end{array}$ & $\begin{array}{c}-0.434 * * * \\
(0.074)\end{array}$ & $\begin{array}{c}-0.435 * * * \\
(0.075)\end{array}$ \\
\hline Duration dependency & Yes & Yes & Yes & Yes & Yes \\
\hline Child birth cohort & Yes & Yes & Yes & Yes & Yes \\
\hline Constant & $-2.103 * * *$ & $-2.137 * * *$ & $-2.070 * * *$ & $-2.117 * * *$ & $-2.091 * * *$ \\
\hline$z$ & $0.841 * * *$ & $0.849 * * *$ & $0.190 * * *$ & $0.820 * * *$ & $0.849 * * *$ \\
\hline$p(\mathrm{pct})$ & 0.590 & 0.597 & 0.908 & 0.603 & 0.584 \\
\hline Number of person-spells & 18967 & 18966 & 18967 & 18967 & 18967 \\
\hline
\end{tabular}




\section{Appendix B}

We estimate wage growth prior to first childbirth as a function of occupation, education, labor market experience (in several polynomials), tenure with the same firm (in several polynomials), region (East versus West Germany), year fixed effects and interactions between year fixed effects and region. Wage growth of person $i$ in year $t$ is defined as $\log \left(\right.$ wage $\left._{t+1}\right)-\log \left(\right.$ wage $\left._{t}\right)$, where wage means gross hourly wage. We choose the covariates in the estimation to maximize the model fit relying on the Akaike information criterion. Occupation is split into eight groups based on the classification of occupations (Klassifikation der Berufe 1992 (KldB 92)) by the Germany Statistical Office (Statistisches Bundesamt). Though the classification is available in the SOEP on a 4-digit level, we are obliged to use relatively wide categories in order to have a reasonable number of observations in each category. The categories are as follows: cat. $1=$ occupations in agriculture, animal husbandry, forestry, horticulture, manufacturing, and other occupations; cat. 2 = technical occupations; cat. 3 = merchants of goods; cat. 4 = merchants of services or associated occupations; cat. 5 = occupations in organizing, administration, or office; cat. $6=$ occupations in health services; cat. $7=$ occupations in social services and education, other humanistic and natural scientific occupations; cat. $8=$ occupations in transport, regulation, security, writing, translation, librarians, artists, and other service occupations. The results of the estimation of wage growth prior to first childbirth are reported in table A4. The overall $R^{2}$ (including the individual effect) of the estimation is $23.6 \%$, i.e., we explain $23.6 \%$ of the variation of wage growth. This might seem low if we consider that we include an individual fixed effect. Note, however, that the periodicity of wage adjustments may matter: Assume we have different types of individuals in the sample, with differing wage growth trajectories, with all individuals receiving a promotion every three years. While the individual effects would be perfect predictors of latent wage growth, the explained variation in wage changes from any one year to the next would only be one third. 
Table A4: Estimation of wage growth prior to first childbirth (dependent variable: $\log \left(\right.$ wage $\left._{t+1}\right)-\log \left(\right.$ wage $\left._{t}\right)$

\begin{tabular}{|c|c|}
\hline \multicolumn{2}{|l|}{ Occupation } \\
\hline Cat. 2 & $\begin{array}{l}-0.015 \\
(0.082)\end{array}$ \\
\hline Cat. 3 & $\begin{array}{c}-0.136 * * \\
(0.067)\end{array}$ \\
\hline Cat. 4 & $\begin{array}{l}-0.069 \\
(0.089)\end{array}$ \\
\hline Cat. 5 & $\begin{array}{l}-0.082 \\
(0.061)\end{array}$ \\
\hline Cat. 6 & $\begin{array}{c}0.101 \\
(0.111)\end{array}$ \\
\hline Cat. 7 & $\begin{array}{c}0.018 \\
(0.080)\end{array}$ \\
\hline Cat. 8 & $\begin{array}{c}-0.128 * * \\
(0.060)\end{array}$ \\
\hline \multicolumn{2}{|l|}{ ISCED educational level } \\
\hline General elementary & $\begin{array}{c}0.103 \\
(0.128)\end{array}$ \\
\hline Middle vocational & $\begin{array}{l}-0.089 \\
(0.125)\end{array}$ \\
\hline Vocational + high school degr (Abitur) & $\begin{array}{l}-0.208 \\
(0.146)\end{array}$ \\
\hline Higher vocational & $\begin{array}{l}-0.174 \\
(0.129)\end{array}$ \\
\hline Higher education & $\begin{array}{l}-0.219 \\
(0.147)\end{array}$ \\
\hline Experience & $\begin{array}{c}-0.341 * * * \\
(0.033)\end{array}$ \\
\hline Experience $^{2}$ & $\begin{array}{c}0.053 * * * \\
(0.008)\end{array}$ \\
\hline Experience $^{3}$ & $\begin{array}{c}-0.005 * * * \\
(0.001)\end{array}$ \\
\hline Experience $^{4}$ & $\begin{array}{c}0.000 * * * \\
(0.000)\end{array}$ \\
\hline Experience $^{5}$ & $\begin{array}{c}-0.000 * * * * \\
(0.000)\end{array}$ \\
\hline Tenure & $\begin{array}{c}0.105 * * * \\
(0.017)\end{array}$ \\
\hline Tenure $^{2}$ & $\begin{array}{c}-0.022 * * * \\
(0.004)\end{array}$ \\
\hline Tenure $^{3}$ & $\begin{array}{c}0.002 * * * \\
(0.000)\end{array}$ \\
\hline Tenure $^{4}$ & $\begin{array}{c}-0.000 * * * * \\
(0.000)\end{array}$ \\
\hline East Germany & $\begin{array}{c}-0.618 \\
(0.791)\end{array}$ \\
\hline Year fixed effects & Yes \\
\hline Year fixed effects X East Germany & Yes \\
\hline Constant & $\begin{array}{c}-0.755^{* * *} \\
(0.207) \\
\end{array}$ \\
\hline No. of person-year obs & 6059 \\
\hline No. of persons & 1295 \\
\hline
\end{tabular}

Note: The reference category for occupation is cat. 1 (details about the occupation categories can be found in the text in appendix B.); the reference category for ISCED educational level is "inadeqQately". Standard errors are in parentheses. $* \mathrm{p}<0.10, * * \mathrm{p}<0.05, * * * \mathrm{p}<0.01$. Data source: SOEP 1984-2013, authors' calculations. 


\section{Appendix C}

Table A5: Estimation of the leave-related wage growth penalty (dependent variable: wage growth at return)

\begin{tabular}{lc}
\hline \hline $\mathrm{g}_{1}$ (occ. cat. 1) & $0.042^{* *}$ \\
& $(0.017)$ \\
$\mathrm{g}_{2}$ (occ. cat. 2) & 0.020 \\
& $(0.032)$ \\
$\mathrm{g}_{3}$ (occ. cat. 3) & $0.028^{* * *}$ \\
& $(0.011)$ \\
$\mathrm{g}_{4}$ (occ. cat. 4) & $0.050^{*}$ \\
& $(0.029)$ \\
$\mathrm{g}_{5}$ (occ. cat. 5) & 0.022 \\
& $(0.016)$ \\
$\mathrm{g}_{6}$ (occ. cat. 6) & 0.012 \\
& $(0.014)$ \\
$\mathrm{g}_{7}$ (occ. cat. 7) & $0.039^{* * *}$ \\
& $(0.012)$ \\
$\mathrm{g}_{8}$ (occ. cat. 8) & 0.008 \\
& $(0.019)$ \\
\hline No. of persons & 541 \\
\hline \hline
\end{tabular}

Note: Details about the occupation categories can be found in appendix B. Standard errors are in parentheses. $* \mathrm{p}<0.10, * * \mathrm{p}<0.05, * * * \mathrm{p}<0.01$. Data source: SOEP 1992-2013, authors' calculations. 
Table A6: Occupation categories

\begin{tabular}{lcc}
\hline \hline Item & Number & Percent \\
\hline Cat. 1 & 43 & 8 \\
Cat. 2 & 24 & 4 \\
Cat. 3 & 68 & 13 \\
Cat. 4 & 46 & 8 \\
Cat. 5 & 144 & 27 \\
Cat. 6 & 81 & 15 \\
Cat. 7 & 79 & 15 \\
Cat. 8 & 58 & 11 \\
Total & 543 & 100 \\
\hline
\end{tabular}

Note: Details about the occupation categories can be found in in appendix B.. Data source: SOEP 1992-2013, authors' calculations.

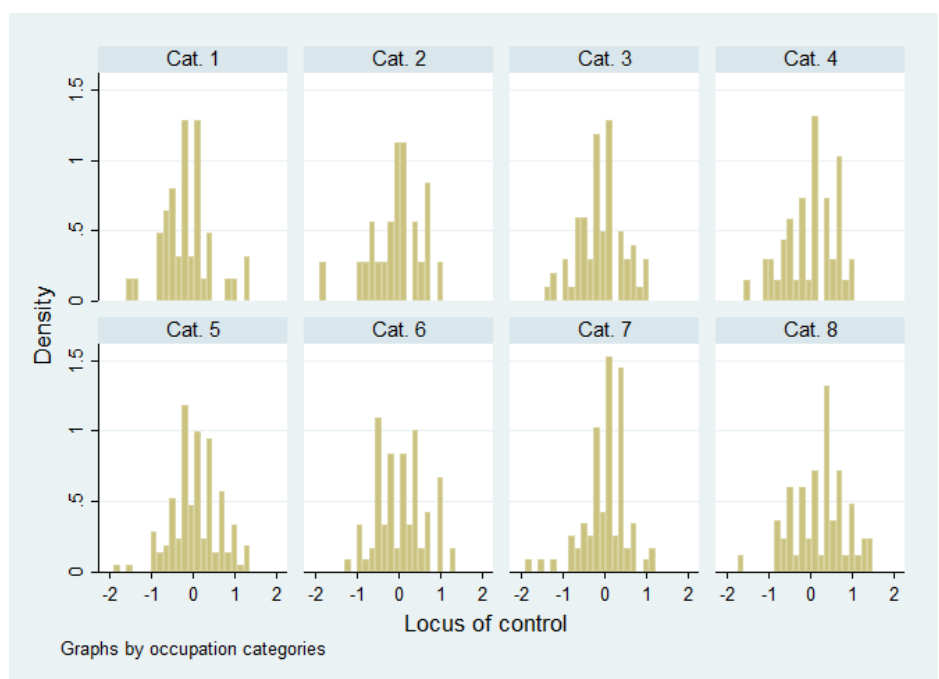

Note: Details about the occupation categories can be found in appendix B.

Figure A1: Distribution of LOC by occupation category 


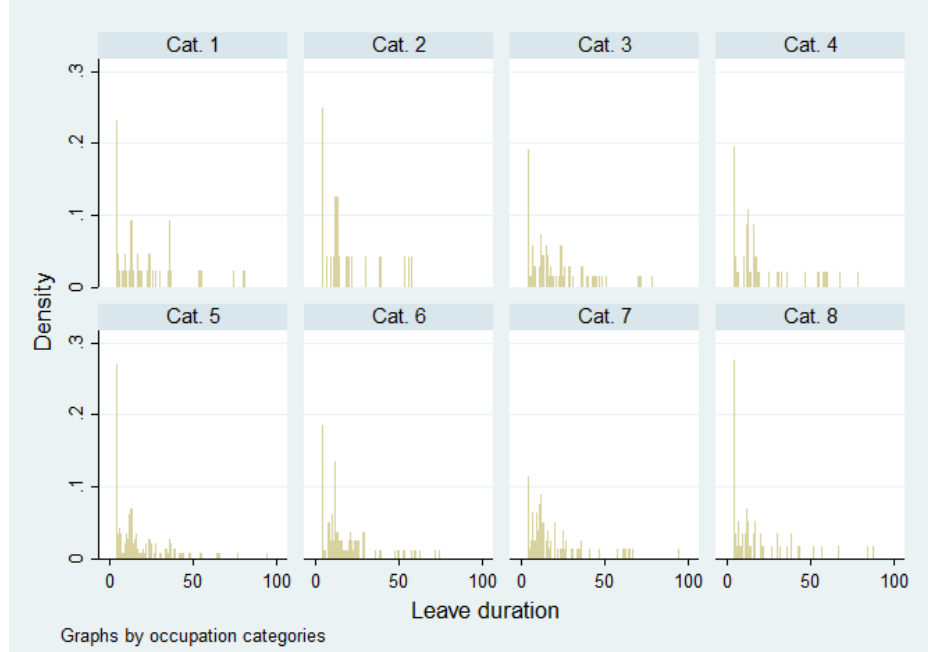

Note: Details about the occupation categories can be found in appendix B.

Figure A2: Distribution of leave duration by occupation category 


\section{References}

Adda, J., C. Dustmann, and K. Stevens (2016). The career costs of children. Journal of Political Economy forthcoming.

Andrisani, P. J. (1977). Internal-external attitudes, personal initiative, and the labor market experience of black and white men. Journal of Human Resources 12(3), 308-328.

Andrisani, P. J. (1981). Internal-external attitudes, sense of efficacy, and labor market experience: A reply to Duncan and Morgan. Journal of Human Resources 16(4), 658-666.

Bergemann, A. and R. T. Riphahn (2009). Female labor supply and parental leave benefits The causal effect of paying higher transfers for a shorter period of time. SOEPpapers 161, DIW, Berlin, Germany.

Bergemann, A. and R. T. Riphahn (2010). The introduction of a short-term earnings-related parental leave benefit system and differential employment effects. SOEPpapers 315, DIW, Berlin, Germany.

Blomeyer, D., M. Laucht, K. Coneus, and F. Pfeiffer (2009). Initial risk matrix, home resources, ability development, and children's achievement. Journal of the European Economic Association 7(2-3), 638648 .

Blundell, R., M. C. Dias, C. Meghir, and J. Shaw (2013). Female labour supply, human capital and welfare reform. mimeo.

Borghans, L., A. L. Duckworth, J. J. Heckman, and B. ter Weel (2008). The economics and psychology of personality traits. Journal of Human Resources 43(4), 972-1059.

Burgess, S., P. Gregg, C. Propper, and E. Washbrook (2008). Maternity rights and mothers' return to work. Labour Economics 15, 168-201.

Caliendo, M., D. Cobb-Clark, and A. Uhlendorff (2015). Locus of control and job search strategies. Review of Economics and Statistics 97(1), 88-103. 
Carneiro, P., C. Meghir, and M. Parey (2011). Maternal education, home environments and the development of children and adolescents. Journal of the European Economic Association forthcoming.

Caspi, A., B. W. Roberts, and R. L. Shiner (2005). Personality development: Stability and change. Annual Review of Psychology 56, 453-484.

Cebi, M. (2007). Locus of control and human capital investment revisited. Journal of Human Resources 42(4), 920-932.

Cobb-Clark, D. and S. Schurer (2013). Two economists musings on the stability of locus of control. Economic Journal 123(570), F358F400.

Coleman, M. and T. DeLeire (2003). An economic model of locus of control and the human capital investment decision. Journal of Human Resources 38(3), 701-721.

Costa Jr, P. T. and R. R. McCrae (1994). Set like plaster? Evidence for the stability of adult personality. In T. F. Heatherton and J. L. Weinberger (Eds.), Can Personality Change?, pp. 21-40. Washington, DC: American Psychological Association.

Cunha, F. and J. J. Heckman (2007). The technology of skill formation. American Economic Review Papers and Proceedings 97(2), 31-47.

Cunha, F. and J. J. Heckman (2008). Formulating, identifying and estimating the technology of cognitive and noncognitive skill formation. Journal of Human Resources 43(4), 738-782.

Cunha, F. and J. J. Heckman (2009). The economics and psychology of inequality and human development. Journal of the European Economic Association 7(2-3), 320-364.

Davies, R. and G. Pierre (2005). The family gap in pay in Europe: A cross-country study. Labour Economics 12, 469-486.

Dechter, E. K. (2014). Maternity leave, effort allocation, and postmotherhood earnings. Journal of Human Capital 8(2), 97-125. 
Dehne, M. and J. Schupp (2007). Persönlichkeitsmerkmale im Sozio-oekonomischen Panel (SOEP) - Konzept, Umsetzung und empirische Eigenschaften. Research Notes 26, DIW, Berlin, Germany.

Flossmann, A. L., R. Piatek, and L. Wichert (2007). Going beyond returns to education: The role of noncognitive skills on wages in Germany. Working paper, University of Konstanz.

Fraley, C. R. and B. W. Roberts (2005). Patterns of continuity: A dynamic model for conceptualizing the stability of individual differences in psychological constructs across the life course. Psychological Review 112, 60-74.

Gutierrez-Domenech, M. (2005). Employment after motherhood: A European comparison. Labour Economics 12, 99-123.

Heckman, J. J. and Y. Rubinstein (2001). The importance of noncognitive skills: Lessons from the GED testing program. American Economic Review Papers and Proceedings 91(2), 145149.

Heckman, J. J. and B. Singer (1984). A method for minimizing the impact of distributional assumptions in econometric models for duration data. Econometrica 52(2), 271-320.

Heckman, J. J., J. Stixrud, and S. Urzua (2006). The effects of cognitive and noncognitive abilities on labor market outcomes and social behavior. Journal of Labor Economics 24(3), $411-482$.

Heineck, G. and S. Anger (2010). The returns to cognitive abilities and personality traits in Germany. Labour Economics 3, 535-546.

Jenkins, S. P. (2005). Survival analysis. Lecture notes manuscript, University of Essex. Online available at http://www.iser.essex.ac.uk/files/teaching/stephenj/ec968/pdfs/ec968lnotesv6.pdf. 
John, O. P. and S. Srivastava (1999). Big Five trait taxonomy. History, measurement, and theoretical perspectives. In L. Pervin and O. P. John (Eds.), Handbook of Personality. Theory and Research, pp. 102-139. New York, NY: Guilford.

Kuhlenkasper, T. and G. Kauermann (2010). Duration of maternity leave in Germany: A case study of nonparametric hazard models and penalized splines. Labour Economics 17, 466473.

Lefebvre, P., P. Merrigan, and M. Verstraete (2009). Dynamic labour supply effects of childcare subsidies: Evidence from a Canadian natural experiment on low-fee universal child care. Labour Economics 16(5), 490-502.

McCrae, R. R. and P. T. Costa (1994). The stability of personality: Observation and evaluations. Current Directions in Psychological Science 3(6), 205-220.

McCrae, R. R. and P. T. Costa Jr (1996). Toward a new generation of personality theories: Theoretical contexts for the Five-Factor Model. In J. S. Wiggins (Ed.), The Five-Factor Model of Personality: Theoretical Perspectives, pp. 5187. New York, NY: Guilford.

McCrae, R. R. and P. T. Costa Jr (1999). A five-factor theory of personality. In L. A. Pervin and O. P. John (Eds.), Handbook of Personality: Theory and Research, pp. 139153. New York, NY: Guilford.

McCrae, R. R. and P. T. Costa Jr (2003). Personality in Adulthood: A Five-Factor Theory Perspective. New York, NY: Guilford Press.

Mueller, G. and E. J. S. Plug (2006). Estimating the effect of personality on male and female earnings. Industrial $\mathcal{E}$ Labor Relations Review 60(1), 1-20.

Noor, N. M. (2002). Work-family conflict, locus of control, and women's well-being: Tests of alternative pathways. Journal of Social Psychology 142(5), 645-662.

Nyhus, E. K. and E. Pons (2005). The effect of personality on earnings. Journal of Economic Psychology 26, 363-384. 
Osborne Groves, M. (2005). How important is your personality? Labor market returns to personality for women in the US and UK. Journal of Economic Psychology 26, 827-841.

Piatek, R. and P. Pinger (2015). Maintaining (locus of) control? data combination for the identification and inference of factor structure models. Journal of Applied Econometrics forthcoming.

Pissarides, C. (2001). Economics of search. In N. Smelser and P. Baltes (Eds.), International Encyclopedia of the Social and Behavioral Sciences, pp. 13760-13768. Elsevier.

Roberts, B. W. and W. F. DelVecchio (2000). The rank-order consistency of personality traits from childhood to old age: A quantitative review of longitudinal studies. Psychological Bulletin 126, 3-25.

Roberts, B. W., N. R. Kuncel, R. Shiner, A. Caspi, and L. R. Goldberg (2007). The power of personality: The comparative validity of personality traits, socioeconomic status, and cognitive ability for predicting important life outcomes. Perspectives on Psychological Science 2(4), $313-345$.

Rotter, J. B. (1966). Generalized expectancies for internal versus external control of reinforcement. Psychological Monographs 80(1).

Schmieder, J. F., T. von Wachter, and S. Bender (2015). The effect of unemployment benets and nonemployment durations on wages. mimeo.

Spinnewijn, J. (2015). Unemployed but optimistic: Optimal insurance design with biased beliefs. Journal of the European Economic Association 13, 130-167.

Uhlendorff, A. (2004). Der Einfluss von Persönlichkeitseigenschaften und sozialen Ressourcen auf die Arbeitslosigkeitsdauer. Zeitschrift für Soziologie und Sozialpsychologie 56(2), 279303.

Uysal, S. D. and W. Pohlmeier (2009). Unemployment duration and noncognitive skills. Working paper, University of Konstanz. 
van den Berg, G. (2001). Duration models: Specification, identification, and multiple durations. In J. Heckman and E. Leamer (Eds.), Handbook of Econometrics, Volume 5. Elsevier.

Wagner, G. G., J. R. Frick, and J. Schupp (2007). The German Socio-Economic Panel Study (SOEP) - scope, evolution and enhancements. Schmollers Jahrbuch 127, 139-169.

Weinhardt, M. and J. Schupp (2011). Multi-itemskalen im soep jugendfragebogen. Data Documentation 60, DIW, Berlin, Germany.

Wichert, L. and W. Pohlmeier (2010). Female labor force participation and the Big Five. Discussion Paper 10-003, ZEW, Mannheim, Germany. 